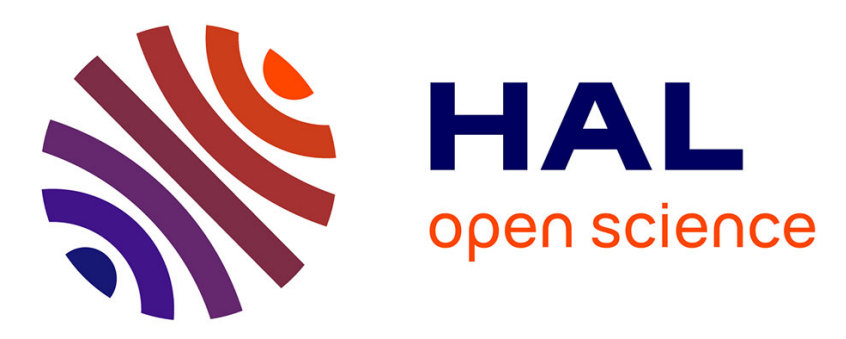

\title{
Interest Term Premiums and C-CAPM: A Test of a Parsimonious Model
}

Hubert de La Bruslerie, Jessica Fouilloux

\section{To cite this version:}

Hubert de La Bruslerie, Jessica Fouilloux. Interest Term Premiums and C-CAPM: A Test of a Parsimonious Model. 2010. halshs-00536924

\section{HAL Id: halshs-00536924 \\ https://shs.hal.science/halshs-00536924}

Preprint submitted on 17 Nov 2010

HAL is a multi-disciplinary open access archive for the deposit and dissemination of scientific research documents, whether they are published or not. The documents may come from teaching and research institutions in France or abroad, or from public or private research centers.
L'archive ouverte pluridisciplinaire HAL, est destinée au dépôt et à la diffusion de documents scientifiques de niveau recherche, publiés ou non, émanant des établissements d'enseignement et de recherche français ou étrangers, des laboratoires publics ou privés. 


\title{
Interest Term Premiums and C-CAPM: A Test of a Parsimonious Model
}

\author{
Hubert de La Bruslerie and Jessica Fouilloux ${ }^{* \dagger}$
}

\begin{abstract}
This paper proposes a consumption-based model that accounts for term premiums of the nominal term structure of interest rates. The driving force behind the model is the looking at the ex ante term premium. Nominal term premiums depend on the volatility processes of real consumption and inflation. When calibrated to US data on interest rates, consumption and inflation, the model accounts for the C-CAPM expectations puzzle. Risk aversion coefficients around 6 are evidenced. The hypothesis of non-constant subjective discount rates is envisaged but successfully validated.
\end{abstract}

JEL: E43, E44, G11, G12

Keywords: C-CAPM, term structure of interest rates, term premium, risk aversion, subjective discount factor.

\footnotetext{
${ }^{*}$ Respectively, professor of Finance, University Paris Dauphine and assistant professor, University of Rennes, mail: hlb@dauphine.fr, jessica.fouilloux@univ-rennes1.fr. This paper benefited from financial support by the Fondation of IGR-IAE Rennes 1.

${ }^{\dagger}$ A first version of the paper benefited from suggestions received at the 2006 AFSE Meeting at Strasbourg and at the 2006 French Finance Association Meeting in Poitiers. We thank participants of these conferences for stimulating discussions. Many thanks are due to A. Lioui, P. Poncet, V. Mignon, P. Roger and an anonymous referee for their comments.
} 


\title{
Interest Term Premiums and C-CAPM: A Test of a Parsimonious Model
}

\begin{abstract}
This paper proposes a consumption-based model that accounts for term premiums of the nominal term structure of interest rates. The driving force behind the model is the looking at the ex ante term premium. Nominal term premiums depend on the volatility processes of real consumption and inflation. When calibrated to US data on interest rates, consumption and inflation, the model accounts for the C-CAPM expectations puzzle. Risk aversion coefficients around 6 are evidenced. The hypothesis of non-constant subjective discount rates is envisaged but successfully validated.

*
\end{abstract}

JEL: E43, E44, G11, G12

Keywords: C-CAPM, term structure of interest rates, term premium, risk aversion, subjective discount factor. 


\section{Interest Term Premiums and C-CAPM: A Test of a Parsimonious Model}

\section{Introduction}

Consumption-investment models are commonly tested with reference to risk bearing assets such as stocks. They are less commonly tested with regard to bonds, i.e. interest rate bearing assets. However, bonds have a time horizon dimension through the current term structure of interest rates (TSIR). Considering 1 year to 30-year bonds, investors are exposed to a risk that is financially expressed by ex post term premiums. Capital asset pricing models should explain not only an individual asset expected return but the whole structure of term premiums. Investors in their consumption choices through time need to consider simultaneously asset of different maturities.

The nominal term structure of interest rates (TSIR) conceals information about future interest rates. In the strict Pure Expectations Hypothesis (PEH), the forward rate is an unbiased forecast of the future spot rate and is particularly efficient in the sense that no other source of information can systematically do better. In a larger view of the Expectations Hypothesis (EH), the $m$ period forward rate is the sum of a forecast of the future spot rate and of a term premium. The traditional expectations hypothesis $(\mathrm{EH})$ of the term structure refers to the idea that forward interest rates are valuable predictors of future values (Hejazi, Lai and Yang, 2000; Backus, Foresi, Mozumbar and $\mathrm{Wu}, 2001$ ). This restrictive version failed against the facts and has been replaced by an approach of the expectations hypothesis that allows term premiums to vary. Empirically, this term premium has appeared effectively unstable through time and positively auto-correlated. (Fama, 1984; Keim and Stambaugh, 1986; Engle and Ng, 1993; Fama, 2006). The slope of the term structure at inception is presented as a measure of the future excess return ensuing from an investment in long-term assets compared with the time horizon of the investor. The expectations approach of the TSIR explains totally the future returns of pure bonds and the information set particularly macro economic variables are useless.

Within the more general framework of a relationship between TSIR and macroeconomic variables, the idea of a direct relationship between the slope of the TSIR and the business cycle has been advocated by Harvey (1988). He finds that the real interest rate slope is a better predictor of the future than current or past consumption data or historical returns on the stock markets. Extensive use of macro variables can also be envisaged to describe the volatility of 
risk factors in the TSIR (Estrella and Hardouvelis, 1991; Ang and Piazzesi, 2003; Ang, Piazzesi and Wei, 2005). Campbell and Cochrane (1999) and Wachter (2006) suggest that bond and equity risk premiums should covary with shocks of aggregate consumption. Brandt and Wang (2003) argue that risk premiums are driven by shocks to inflation as well as aggregate consumption; both notably macroeconomic shocks. More recently, Ludvinston and Ng (2009) find that principal components related to real economic activity have significant predictive power for excess bond returns.

The C-CAPM offers a theoretical answer to the link between macroeconomic variables, the actual TSIR and the forecasted excess bond premiums. Considering interest rates as assets, we can refer to the basic consumption-investment model to explain the agent's expected returns over his investment period and consequently the term premium values. In the standard CCAPM (Lucas, 1978; Breeden, 1979), the representative agent faces a simple choice between immediate real consumption or investment in pure financial assets delivering an inflation risked future cash flow. This model has been refereed to explain the equilibrium excess returns of financial assets, particularly the set of zero coupon bonds that defines the TSIR. For instance, Campbell (1986), Backus, Gregory and Zin (1989), and Campbell and Viceira (2001) use that model to calculate the theoretical value of the term premiums (expressed as excess return premiums). They particularly highlight the aggregated consumption and the uncertainty of interest rates as determinants of term premiums. These studies all assume that, for a given maturity, the term premiums are constant through time.

The standard C-CAPM makes the term premium depends on the conditional variance and covariance of consumption, but also on risk aversion and time discounting parameters. An empirical test of an unconditional version of C-CAPM in a world without inflation risk was proposed by Weil (1989) and leads to the well-known "risk-free rate puzzle". Lee (1995) showed that the risk aversion coefficient that is implicit in the average ex post value of the three-month term premium is 5 , which is within the range of values considered as normal. $\mathrm{He}$ tested several explanatory variables and confirmed the validity of the consumption conditional variance (aside from the structure of the offered debt). The conditional variances of interest rates and of the price index are not found significant.

A theoretical way to improve the consumption asset pricing model is to include sophisticated utility functions (i.e., internal habits, Sundaresan, 1989, or external habits, Campbell and 
Cochrane, 1999) or long-run consumption dynamics. Chacko and Viceira (2005) examine the optimal consumption and portfolio-choice problem of long-horizon investors in a noninflationary context with a riskless asset with constant return. Interest rates are only nominally risk-free assets but are exposed to an inflation risk. This point has been particularly emphasized since Breeden (1986). His inflation-adjusted C-CAPM model integrates the volatilities of the consumption and the inflation processes and, as a consequence, the covariance term between the last two. This approach will be followed hereafter.

More technical aspects are salient in the tests of consumption equilibrium models and rely to theoretical questions. Harvey's (1988) measure of the forecasted growth of real consumption (and wealth) is based on the ex post growth that effectively occurs. In his test, he considers an ex post estimate of consumption, despite the fact that the investment-consumption model looks at the ex ante demand of consumption in the future. This can lead to erroneous model acceptance as mentioned by Campbell and Cochrane (2000), who outlined the importance of errors in the estimates of the consumption. A time varying consumption variance appears to be of the utmost importance in empirical tests. Del Castillo and Fillion (2002) model the conditional consumption variance using an AR-ARCH process. The process explains both the heteroscedastic volatility of the term premium and its autocorrelation. Del Castillo and Fillion also showed that with "reasonable" values of the risk aversion coefficient (i.e., between 5 and 10), their model fits well with the average observed term premium in the Canadian money market over the period of 1960-2000. Balfoussia and Wickens (2004) used a multivariate GARCH model to explain the US bond excess return. They consider consumption, production and inflation as macroeconomic variables. They find that inflation has a positive influence in explaining the term premium, but consumption seems to play a negative role. The inflation risk factor appears to be considered in a real asset pricing model both on the theoretical and empirical ground. Following the argument initiated by Mankiw and Zeldes (1991), Paiella (2004) or Malloy et al. (2009) underline the importance of considering microeconomic data to identify the effective stockholders who are exposed to consumption risk within a C-CAPM framework. This analysis yields risk aversion coefficients of between 7 and 14 for effective bondholders (and between 15 and 25 for effective stockholders) ${ }^{1}$. C-CAPM seems to improve more when looking at interest rates, i.e., time risky assets, than when looking at standard assets bearing a large idiosyncratic risk. 
The standard microeconomic time allocation model assumes a unique and constant psychological factor to discount future utility values. It is traditionally assumed that the psychological impatience rate (or psychological price of time) is the same whatever the age of the investor or his time horizon. This convenient hypothesis allows the separation of the investment-consumption choices at any period in the future. The issue of hyperbolic individual discounting has been raised by Laibson $(1996,1998)$. On a theoretical basis, it harms the time consistency hypothesis and the rationality of the consumer-investor's intertemporal choices (Strotz, 1956). Under certain conditions of the utility function, the psychological time preference rates of the representative agent may not be constant within a pluri-temporal framework (Laibson, 1998). Lengwiler (2005) shows that decreasing interest rates can be rationally explained by the aggregation of exponentially discounting agents. The standard CCAPM model is enlarged to allow a non-constant subjective discount factor (Laibson, 1996; Laibson et al., 2004). This class of non-standard model, which, for instance, refers to hyperbolic subjective discount functions, is mentioned as a way to improve consumption-investment intertemporal choices.

The motivation of the paper is to propose a consumption-based model that accounts for term premiums of the nominal term structure of interest rates. The driving force behind the model is the looking at the ex ante term premium. Nominal term premiums depend on the volatility processes of real consumption and inflation. A parsimonious model allows us to test a multivariate C-CAPM considering the TSIR globally, from 1- to 10-year maturities.

Our paper makes two contributions to the literature. First, the paper relies on the modeling of the ex ante consumption volatility and the use of a parsimonious three-factor model integrating the inflation risk. We link a real C-CAPM version to the bond market and the TSIR. Second, US Treasury bond data empirically support the model. When calibrated to US interest rates, consumption and inflation, the model accounts for the expectations puzzle. We outline more accurate risk aversion estimates. The use of an unrestricted model with non-linear subjective individual discount factors is not confirmed by our data.

Our test focuses on the central role of the conditional volatility of consumption. Hereafter, consumption follows an AR-ARCH process. We show that term premiums are linked to the conditional volatility of consumption considered from an ex ante point of view. The empirical test compares the result using an ex ante and parsimonious approach of the future volatility of 
consumption and other estimates of the consumption volatility. The theoretical model that emphasizes the ex ante equilibrium between volatility and expected return fits best and supports the rational view of setting the term structure as a solution for an investment-consumption choice. The relationship proves to be significant. In other words, the current term structure gives valuable information on the uncertain future process followed by consumption, particularly its volatility. Prior tests were often based on ex post values of consumption, and sometimes on unconditional measures of its variance. When used, these variables are not successful in our tests.

Our empirical test is based on term premiums, not on pure spot interest rates. It allows canceling the accumulation trend in the consumption model, to ignore inflation and to focus only on the conditional variance of the process. We use US data to empirically highlight a positive relationship between the term premiums, i.e. the term structure slope, and the conditional variance of consumption. The standard C-CAPM is based on an exponential discounting of future utility and a constant psychological rate of impatience of the representative agent. This hypothesis is sometimes linked with poor empirical evidence of risk aversion estimates and with the "risk-free rate puzzle". Non-constant subjective discount rates are envisaged to introduce the possibility of a non-flat term structure of subjective discount rates.

The outline of the paper is as follows. Section 2 describes the estimation of the consumption and the inflation processes and the development of the model, which is then empirically tested. Section 3 describes the results obtained from US bond market data. A conclusion follows.

\section{Model}

The model referenced in our paper is the consumption-based capital asset pricing model. The representative agent is facing a simple choice between immediate consumption and investment in pure financial assets such as zero-coupon bonds delivering a risk-free future cash-flow. His setting considers any point in the future. So the C-CAPM equilibrium is directly connected to the whole term structure (Breeden, 1986). The ex ante term premium (or, equivalently, the future expected return) derived from the C-CAPM depends on two behavioral parameters: the 
agent's risk aversion and his subjective time impatience rate. It also depends on one major risk factor variable: the conditional variance of the real consumption process.

The test focuses on the key roles of the conditional volatilities of consumption and inflation as risk factors. Hereafter, real consumption follows an AR-ARCH process. This allows the testing of a simple version of the standard C-CAPM using the next period volatilities of consumption and inflation. Due to heteroscedasticity, we have to forecast the conditional volatility of consumption as considered from an ex ante point of view. We consider a multivariate AR$\mathrm{ARCH}$ process to model the inflation volatility process and the covariance between consumption and inflation. The empirical test compare the result obtained using the ex ante approach of the future variance and covariance to other estimates.

\subsection{The Standard C-CAPM Model}

The intertemporal choice between immediate consumption and investment is the standard model, where pure risk-free assets bearing interest rates allow the investor to defer consumption into the future. The standard investment-consumption model considers an agent who maximizes a time separable expected utility:

$$
\operatorname{Max} E_{t}\left[\sum_{j=0}^{\infty} \delta^{j} U\left(C_{t+j}\right)\right]
$$

with:

$\delta$ : discount factor associated with the psychological impatience rate for one period $(\delta<1)$

$C_{t+j}$ real consumption at time $t+j$

$U\left(C_{t+j}\right)$ : consumption utility at time $t+j$

The representative investor-consumer can buy or sell any financial asset $i$ with an uncertain expected return. The asset allows him to consume real units of real goods at time $t+j$ in the future (from time $t+j$ to $t+j+1$ ). He will consider globally this problem looking at different date in the future for different time horizon $j$. He is time consistent. The first-order condition of the Euler equation, which defines the consumption-investment optimal choice between time $t$ now and time $t+j$ in the future, is: 


$$
U^{\prime}\left(C_{t}\right)=\delta^{j} \cdot E_{t}\left[R_{t+j}^{i} \cdot U^{\prime}\left(C_{t+j}\right)\right]
$$

$R_{t+j}^{i}$ : uncertain return of any asset $i$ giving cash-flows at time $t+j$ or later (to avoid the reinvestment problem).

The standard model assumes a representative agent with a power utility function U:

$$
U\left(C_{t}\right)=\frac{C_{t}^{1-\alpha}-1}{1-\alpha}
$$

where $\alpha$ is a relative risk aversion coefficient. If $\alpha$ is close to 1 , the utility function $U(C)$ converges toward $\log (C)$. A property of the power utility function is its "scale invariance": with a constant return distribution, the coefficient of relative risk aversion (CRRA) is always $\alpha$ and does not vary through time, even when the aggregated consumption or the wealth levels improve in the economy. Equation (2) is in real term and is true for any asset giving one uncertain and certain future cash-flow. It is also true for any $j$ corresponding to the time horizon choice. If the asset is the pure certain risk free cash flow at the time horizon, the risk free asset and its return can be factorized out. So the series of condition (2) over the $j$ time horizon refer directly to the (real) term structure (Breeden, 1986).

The condition (2) holds for any asset and we now consider among the $i$ risky assets a subset of nominal risk-free assets on the investment time horizon: they consist of zero coupon bonds maturing precisely at $t+j$. Their nominal cash-flow is unique and not exposed to a default. They are characterized by the subscript $j$ corresponding to their maturity. These assets will describe the nominal TSIR. Their real return ${ }_{t} R_{j}$ is not known at time $t$ due to the inflation risk and it is expressed in the periodically (annually) capitalized form $(1+R)^{j}$. The inflation risk makes the real return on the $j$ maturity zero coupon bond uncertain. Combining equations (2) and (3) gives:

$$
\delta^{j} \cdot E_{t}\left[\left(\frac{C_{t+j}}{C_{t}}\right)^{-\alpha}{ }_{t} R_{j}\right]=1
$$

Equation (4) is in real terms. Taking the logarithm of (4) and using the assumption that consumption and inflation uncertainty are conditionally lognormal: 


$$
\begin{aligned}
& j \cdot \log \delta+E\left[\log \left({ }_{t} R_{j}\right)\right]+E_{t}\left[\log \left(\frac{C_{t+j}}{C_{t}}\right)^{-\alpha}\right]+\frac{\alpha^{2}}{2} \operatorname{var}_{t}\left[\log \left(\frac{C_{t+j}}{C_{t}}\right)\right] \\
& +\frac{1}{2} \operatorname{var}_{t}\left[\log \left({ }_{t} R_{j}\right)\right]-\alpha \operatorname{cov}\left[\log \frac{C_{t+j}}{C_{t}}, \log _{t} R_{j}\right]=0
\end{aligned}
$$

We use the convention that lower-case $c$ and $r$ correspond to logs of variables $C$ and $R$, respectively, where $r$ is now an annual equivalent rate $^{2}$. We recall that $R$ is a real uncertain rate of return of a pure bond asset; the stochastic part of it is due to the log inflation process $\Delta i^{3}$ :

$$
E_{t}\left({ }_{t} r_{j}\right)=-\log \delta+\frac{\alpha}{j} \cdot E_{t}\left[\Delta c_{t, t+j}\right]-\frac{\alpha^{2}}{2 \cdot j} \operatorname{var}_{t}\left(\Delta c_{t, t+j}\right)-\frac{1}{2 \cdot j} \operatorname{var}_{t}\left(\Delta i_{t, t+j}\right)-\frac{\alpha}{j} \operatorname{cov}_{t}\left(\Delta c_{t, t+j}, \Delta i_{t, t+j}\right)(6)
$$

Equation (6) was first derived by Hansen and Singleton (1983) and is stated directly in real terms. They focus on any arbitrary next time horizon choice $t+1$. However, the problem is general so equation (6) stands for any investment maturity $j$ (Breeden, 1986). This explains why the term structure of interest rates is globally involved. It gives the expected uncertain return of a $j$ maturity nominal bond in a world with inflation. It states that at time $t$, a close and direct relationship exists between the investment-consumption choices of the agent looking to any time horizon $j$ and the equilibrium in the interest rate market, or more precisely, the form of the TSIR for $j$ moving from 1 to $n$. If the investor becomes more impatient, his psychological discount factor $\delta$ decreases (from 1 toward zero), and the (real) interest rate in the market should increase to encourage him to defer his consumption forward into the future. Moreover, interest rates are higher if the variance of the consumption growth is low: a lower uncertainty regarding the process followed by the future consumption means a lower need for precautionary saving and, ceteris paribus, implies higher interest rates in the market.

\subsection{Expression of the Term Premium}

The standard C-CAPM model (6) is set at time $t$. We now look forward to the time $t+1$ equilibrium rate and taking expectations from $t$, we obtain: 


$$
\begin{aligned}
& E_{t}\left({ }_{t+1} r_{j}\right)=-\log \delta+\frac{\alpha}{j-1} \cdot E_{t}\left[\Delta c_{t+1, t+j}\right]-\frac{\alpha^{2}}{2 \cdot(j-1)} E_{t} \operatorname{var}_{t+1}\left(\Delta c_{t+1, t+j}\right) \\
& -\frac{1}{2 .(j-1)} E_{t} \operatorname{var}_{t+1}\left(\Delta i_{t+1, t+j}\right)-\frac{\alpha}{(j-1)} \cdot E_{t} \operatorname{cov}_{t+1}\left(\Delta c_{t+1, t+j}, \Delta i_{t+1, t+j}\right)
\end{aligned}
$$

We see in (7) that the variance of the future changes in real consumption in right-hand side (RHS) is different and is time varying. The same phenomenon is observed for the variance of future inflation changes and for the future covariance between consumption and inflation. It is conditioned by the information set available at the beginning period from which the expectation is set. The forecasted variance is that of the consumption (resp. inflation) over the $[t+1, t+j]$ period in the future. Uncertainty in interest rates entails a risk premium in the nominal TSIR equilibrium. According to the expectations theory, we know that the term premium can be defined either as an excess return over the risk-free rate on a given time horizon or as a bias between the nominal forward rate at time $t$ and the future nominal spot rate at time $t+1$. The latter approach is followed. For a pure loan:

${ }_{t, t+1} f_{j-1}=E_{t}\left({ }_{t+1} r_{j-1}^{n o m}\right)+{ }_{t, t+1} p_{j-1}$

${ }_{t, t+1} f_{j-1}: \log$ of the nominal forward rate at $t$ for a $j-1$ maturity loan at $t+1$

${ }_{t, t+1} p_{j-1}$ : ex ante term premium at time $t$ between the forward rate and the future expected nominal spot rate, $r^{\text {nom }}$

$E\left(r^{\text {nom }}\right)=E(r)+E\left(\Delta i_{t+1, t+j}\right)$, where the expected nominal interest rate $r^{\text {nom }}$ is equal to the future real interest rate plus the inflation variation over the $t+1 / t+j$ period

The nominal equilibrium of the term structure at any given time $t$ links the interest rates on the entire horizon $t+1$ to $t+j$. It also involves the expectations of future interest rates by integrating a risk premium $p$ (equation 8). It reconciles any maturity $j$ bond to the (expectation of) the interest rates of maturity $j-1$ zero coupon at time $t+1$ (or identically, referring to forward rates, to the risk-free pure bonds of maturity $j$ at time $t+1$ ). We know that the forward rates are tautological results of the nominal TSIR:

$$
{ }_{t} r_{1}^{n o m}+(j-1)_{t, t-1} f_{j-1}=j \cdot r_{j} r_{j}^{n o m}
$$


Introducing (8) and (9) in relation to (7), the inflation variation in the nominal rates cancels out. Recalling that the real rate of return is uncertain at date $t$, we obtain:

$$
\begin{aligned}
& j \cdot E_{t}\left({ }_{t} r_{j}\right)-E_{t}\left({ }_{t} r_{1}\right)-(j-1)_{\cdot_{t+1}} p_{j-1}=-(j-1) \log \delta+\alpha \cdot E_{t}\left\lfloor\Delta c_{t+1, t+j}\right\rfloor \\
& -\frac{\alpha^{2}}{2} E_{t} \operatorname{var}_{t+1}\left(\Delta c_{t+1, t+j}\right)-\frac{1}{2} E_{t} \operatorname{var}_{t+1}\left(\Delta i_{t+1, t+j}\right)-\alpha \cdot E_{t} \operatorname{cov}_{t+1}\left(\Delta c_{t+1, t+j}, \Delta i_{t+1, t+j}\right)
\end{aligned}
$$

We replace ${ }_{t} r_{j}$ and ${ }_{t} r_{l}$ using the real expected return at date $\mathrm{t}$ (see eq. 6). Introducing the term premium, which has no inflation dimension, into the real pricing kernel (5) yields a simplified expression. Both the $\Delta c$ term of expected changes in (real) consumption and the psychological discount factor term $\delta$ disappear. To simplify the notation, we use the following variables:

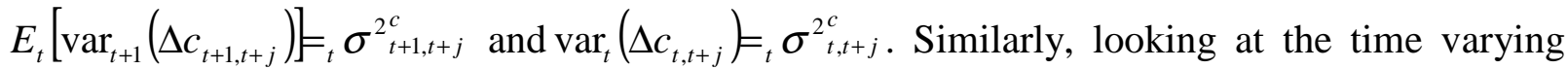
inflation variance and covariance, we use: $\operatorname{var}_{t}\left(\Delta i_{t, t+j}\right)={ }_{t} \sigma_{t, t+j}^{i}$ and $\operatorname{cov}_{t}\left(\Delta c_{t, t+j}, \Delta i_{t, t+j}\right)={ }_{t} \sigma_{t, t+j}^{i c}$. We obtain:

$$
\begin{aligned}
& { }_{t+1} p_{j-1}=-\frac{\alpha^{2}}{2 \cdot(j-1)}\left[\sigma_{t}^{2 c}{ }_{t, t+j}^{c}-{ }_{t} \sigma_{t, t+1}^{2^{c}}-{ }_{t} \sigma_{t+1, t+j}^{2 c}\right] \\
& -\frac{1}{2 .(j-1)}\left[{ }_{t} \sigma^{2}{ }_{t, t+j}^{i}-{ }_{t} \sigma^{2^{i}}{ }_{t, t+1}-{ }_{t} \sigma^{2^{i}}{ }_{t+1, t+j}\right]-\frac{\alpha}{2 .(j-1)}\left[{ }_{t} \sigma_{t, t+j}^{i c}-{ }_{t} \sigma_{t, t+1}^{i c}-{ }_{t} \sigma_{t+1, t+j}^{i c}\right]
\end{aligned}
$$

The equilibrium relationship (11) is a parsimonious model. It states that the nominal term premium is homogeneous with the changes in the volatility of the future real consumption growth, in the volatility of inflation and in the covariance between the two. It focuses on the joint consumption and inflation volatility process and simplifies the traditional equilibrium relationship by canceling out the expected consumption growth and inflation variation terms over the time horizon $j$. Considering term premiums (or, more globally, zero coupon asset returns) allows simplified and more robust empirical tests of consumption models. The heteroscedasticity of consumption (and inflation) changes becomes the key point (for more details on the conditional variance, see appendix A). In the general case of conditional variance in consumption (or inflation) changes, variance is not constant through time $\sigma_{t, t+1}^{2} \neq \ldots \neq \sigma_{t+j, t+j+1}^{2}$. We assume a bivariate AR(1) stationary process ruling consumption and inflation:

$$
\begin{aligned}
& \Delta c_{t+1, t+2}=\mu_{c}+\rho_{c} \cdot \Delta c_{t, t+1}+\varepsilon_{t+2}^{c} \\
& \Delta i_{t+1, t+2}=\mu_{i}+\rho_{i} \cdot \Delta i_{t, t+1}+\varepsilon_{t+2}^{i}
\end{aligned}
$$


For a time horizon of one period starting at $t$ and writing $v_{j}$ the (one period) innovation variance in (12) for time $t+j$ as forecasted at $t$ :

$$
{ }_{t} \sigma_{t, t+1}^{2^{c}}=E_{t}\left(\varepsilon^{2_{t+1}^{c}}\right)={ }_{t} v_{1}^{c}
$$

For a time horizon of $j$ periods ahead considered at time $t$ :

$$
{ }_{t} \sigma^{2_{t, t+j}^{c}}=\left(1+\rho_{c}+\ldots+\rho_{c}^{j-1}\right)^{2}{ }_{t} v_{1}^{c}+\left(1+\rho_{c}+\ldots+\rho_{c}^{j-2}\right)^{2} \cdot{ }_{t} v_{2}^{c}+\ldots+{ }_{t} v_{j}^{c}
$$

Relationships similar to (13) and (14) lead to the replacement of subscript $c$ with $i$ in the innovation formula of the time varying variance of the inflation process. We can also derive similar formulas to express the covariance in terms of one period ahead covariance innovation, ${ }_{t} \boldsymbol{v}_{j}^{c i}$. Combining equations (13) and (14) into (11) gives:

$$
\begin{aligned}
& { }_{t+1} p_{j-1}=-\frac{\alpha^{2}}{2 \cdot(j-1)}\left[\left(\left(1+\rho_{c}+\rho_{c}^{2}+\ldots+\rho_{c}^{j-1}\right)^{2}-1\right) \cdot v_{1}^{c}\right] \\
& -\frac{1}{2 \cdot(j-1)}\left[\left(\left(1+\rho_{i}+\rho_{i}^{2}+\ldots+\rho_{i}^{j-1}\right)^{2}-1\right) \cdot v_{t}^{i}\right] \\
& -\frac{\alpha}{(j-1)}\left[\left(\left(1+\rho_{c}+\rho_{c}^{2}+\ldots+\rho_{c}^{j-1}\right)\left(1+\rho_{i}+\rho_{i}^{2}+\ldots+\rho_{i}^{j-1}\right)-1\right) \cdot v_{1}^{c i}\right]
\end{aligned}
$$

Equivalently:

$$
\begin{aligned}
& { }_{t+1} p_{j-1}=-\frac{\alpha^{2}}{2 \cdot(j-1)}\left[\left(\frac{\left(1-\rho_{c}^{j}\right)^{2}}{\left(1-\rho_{c}\right)^{2}}-1\right)\right] \cdot{ }_{t} v_{1}^{c}-\frac{1}{2 \cdot(j-1)}\left[\left(\frac{\left(1-\rho_{i}^{j}\right)^{2}}{\left(1-\rho_{i}\right)^{2}}-1\right)\right] \cdot{ }_{t} v_{1}^{i} \\
& -\frac{\alpha}{(j-1)}\left[\left(\left(\frac{\left(1-\rho_{c}^{j}\right)}{\left(1-\rho_{c}\right)}\right)\left(\frac{\left(1-\rho_{i}^{j}\right)}{\left(1-\rho_{i}\right)}\right)-1\right)\right] \cdot{ }_{t} v_{1}^{c i}
\end{aligned}
$$

The term premium for maturity $j$ is an inverse function of the maturity $j$ of the zero coupon bond. The sign of (15) is not defined and depends on the magnitude and sign of $\rho$. Its absolute value increases with the risk aversion coefficient. Equation (15) underlines a direct relationship between the size of the term premium and the conditional consumption and inflation volatilities over the next period. The term premium appears logically time varying with the conditional volatility. It also depends on the correlation coefficient, which defines the process followed by 
consumption and inflation during two successive periods. No constant appears. The equation (15) model is parsimonious in the sense that it only depends on the innovation variances and covariance of the consumption and inflation process. Neither the subjective discount factor over the maturity $j$, nor the changes in consumption and inflation over the period $j$ appear in equation (15).

\subsection{Introducing Non-Constant Subjective Discount Factors}

If we reject the uniqueness of the time discount rate $\delta$, we need to introduce a complete set of subjective discount factors such as $\delta_{1} \neq \delta_{2} \ldots \neq \delta_{n}$ in the investor's choice for any maturity horizon from 1 to $n$ in equation (1). The $\delta_{j}$ factors are less than one and will define a term structure of the subjective price of time of the representative agent $\tau_{j}=-\log \left(\delta_{j}\right)$. The intertemporal consumption-investment choice with regard to the horizon $t+j$ introduces the relevant time discount for that period $\delta_{j}$. Using the same assumptions leading to the C-CAPM (power utility function, joint lognormal process), a relationship similar to the standard model is obtained, but this one now refers to the relevant subjective discount rate for the time horizon $j$, $\delta_{j}:$

$$
E_{t}\left({ }_{t} r_{j}\right)=-\log \delta_{j}+\frac{\alpha}{j} \cdot E_{t}\left[\Delta c_{t, t+j}\right]-\frac{\alpha^{2}}{2 \cdot j} \operatorname{var}_{t}\left(\Delta c_{t, t+j}\right)-\frac{1}{2 \cdot j} \operatorname{var}_{t}\left(\Delta i_{t, t+j}\right)-\frac{\alpha}{j} \operatorname{cov}_{t}\left(\Delta c_{t, t+j}, \Delta i_{t, t+j}\right)\left(6^{\prime}\right)
$$

Turning to the term premium relationship, the psychological prices of time no longer cancel out. The expected equilibrium value of the term premium is now:

$$
\begin{aligned}
& { }_{t+1} p_{j-1}=\frac{\left(\log \delta_{1}+(j-1) \log \delta_{j-1}-j \cdot \log \delta_{j}\right)}{(j-1)} \\
& -\frac{\alpha^{2}}{2 \cdot(j-1)}\left[\left(\frac{\left(1-\rho_{c}^{j}\right)^{2}}{\left(1-\rho_{c}\right)^{2}}\right)-1\right] \cdot{ }_{t} v_{1}^{c}-\frac{1}{2 \cdot(j-1)}\left[\left(\frac{\left(1-\rho_{i}^{j}\right)^{2}}{\left(1-\rho_{i}\right)^{2}}\right)-1\right] \cdot{ }_{t} v_{1}^{i} \\
& -\frac{\alpha}{(j-1)}\left[\left(\frac{\left(1-\rho_{c}^{j}\right)}{\left(1-\rho_{c}\right)}\right)\left(\frac{\left(1-\rho_{i}^{j}\right)}{\left(1-\rho_{i}\right)}\right)-1\right] \cdot v_{1}^{c i}
\end{aligned}
$$

A new constant appears as a first term on the (RHS) of (15'). It represents a non flat time preference and gives a permanent component to the value of the term premium. This constant term is specific for a given $j$ horizon. We will hereafter test the hypothesis of a possible non-flat term structure of psychological prices of time. If a significant constant term results from the 
empirical test of (15), we will reject the hypothesis of a constant and unique psychological impatience rate.

\section{Empirical Test and Results}

Relationships (15) and (15') lead us to test a simple three-variable model that links the term premiums and the conditional variances and covariance of consumption and inflation. This model, in its non-restricted form, allows a constant to compare the standard C-CAPM with a non-constant subjective discount rate. The time data of ex post consumption are not relevant here. In the model, we need to consider the ex ante conditional variance as forecasted by the investor. The term premium is also not ex ante observable. However, the ex post term premium values are unbiased compared with the ex ante values asked for by the investor, which are implicit in the TSIR equilibrium. The term premium variable $p$ is the same whether looking at real or nominal interest rates and returns. We will consider two different forecasting horizons $h$ of 6 and 12 months, respectively. The unitary period in equations (15) and (15') needs to be specified more precisely, ${ }_{t, t+h} \hat{p}_{j}={ }_{t, t+h} p_{j}+\eta_{t+h}$, where $\hat{p}$ is the ex post term premium measured at time $t+h, j$ is the remaining maturity of the zero coupon bond at $t+h$ and $\eta$ is a combination of expectation errors and measurement errors.

The equilibrium relationships (15) and (15') are nonlinear with regard to the core parameter of the C-CAPM model, i.e., the risk aversion coefficient $\alpha$. Thus, we consider a nonlinear estimate. We also estimate a direct linear form of equations (15) and (15'). For a given maturity $j$, the following linear regression tests the relationship between term premiums and the conditional variance and covariance:

$$
{ }_{t+h} \hat{p}_{j}=k_{j}^{0}+k_{j, t}^{1} v_{t, t+h}^{c}+k_{j, t}^{2} v_{t, t+h}^{i}+k_{j, t}^{3} v_{t, t+h}^{c i}+\eta_{t}
$$

Five different maturities spanning from 1 to 9 years at the end of the forecasting period (i.e., $j=1,2,4,6$ and 9) are considered. The nonlinear (15) and linear (16) equations are tested in a multivariate setting, looking jointly at five term premiums on zero coupon bonds held during $h$ months and with a remaining maturity of $j$ years at the end of the holding (and forecasting) period. For instance, ${ }_{1} p_{9}$ is the term premium measured by the bias between the spot interest rate of a nine-year pure bond one year later compared with the forward rate one year earlier. 


\subsection{Data}

The term premiums are estimated using American bond data. Zero coupon curves are calculated from actuarial yields of US Treasury bills and bonds. Data come from the Federal Reserve System (file H15). We use generic yields of constant maturity Treasury bonds (CMT yields) with, respectively, 6 months and 1, 2, 3, 5, 7 and 10 years to maturity ${ }^{4}$. Monthly data are extracted over the period of January 1971-September 2005. Data considered are yields of the last business day of the month. We generate the yields corresponding to the unavailable maturities of 4, 6, 8 and 9 years by interpolation ${ }^{5}$. Theoretical spot zero coupon rates are extracted using a bootstrap algorithm starting from the 6-month and 1-year Treasury interest rates that are zero coupon bonds. The same method is implemented using the same set of data by Chun (2005). We use the logs of pure spot interest rates to calculate the forward rates over the two different forecasting horizons of 6 months and 1 year. In the first set of data, we have the forward rates for 1- to 9-year pure loan maturities at the end of a 6-month forecasting period. In the second set, we have the same rates at the end of a 1-year deferred period. The term premiums are therefore the simple difference between these forward rates and the real spot interest rates that are observed 6 months or 1 year later. They are available, respectively, over the periods of 1971:07-2009:02 and 1972:01-2009:02.

Tables 1 and 2 present descriptive statistics of the ten term premiums considered in our test. We recall that term premiums are measured as a bias in forecasting. Foreseeing short-term rates is more difficult than foreseeing long-term rates, with larger average errors. Term premiums appear as highly unstable with large ex post variances. They are also strongly correlated with a large and positive first-order autocorrelation. The second-order correlation is negative for both forecasting horizons. A significant partial autocorrelation lasts up to the fourth order. The overlapping of monthly data over a 6- or 12-month horizon explains the statistically significant autocorrelation when considering anticipation for term premiums from $t$ to $t+h$.

Table 1: Descriptive statistics of term premiums for a 6-month horizon (Monthly data from 1971:6 to 2009:02; constant maturity yields from Treasury Bonds data with 2, 3, 5, 7 and 10 years of maturity; zero coupon rates derived from yields using a bootstrap procedure; $N$ : number of observations; p: term premium, i.e., forward 6-month interest rates of 1, 2, 4, 6 and 9 years minus corresponding realized spot rates 6 months later)

\begin{tabular}{clllll|}
\hline $\begin{array}{c}\text { Term } \\
\text { premium }\end{array}$ & $\mathbf{N}$ & Mean & Std Error & Minimum & Maximum \\
\hline$p_{1}$ & 453 & 0.003705 & 0.013288 & -0.050796 & 0.053894 \\
\hline
\end{tabular}




\begin{tabular}{llllll}
\hline$p_{2}$ & 453 & 0.002747 & 0.012084 & -0.046010 & 0.047987 \\
\hline$p_{4}$ & 453 & 0.002180 & 0.010572 & -0.038883 & 0.042410 \\
\hline$p_{6}$ & 453 & 0.001810 & 0.009543 & -0.034815 & 0.038872 \\
\hline$p_{9}$ & 453 & 0.001239 & 0.008451 & -0.030197 & 0.034509 \\
\hline
\end{tabular}

Table 2: Descriptive statistics of term premiums for a 1-year horizon

(Monthly data from 1971:12 to 2009:02; constant maturity yields from Treasury Bonds data with 2, 3, 5, 7 and 10 years of maturity; zero coupon rates derived from yields using a bootstrap procedure; $N$ : number of observations; $p$ : term premium, i.e., forward 12-month interest rates of 1, 2, 4, 6 and 9 years minus corresponding realized spot rates one year later)

\begin{tabular}{|cccccc|}
\hline $\begin{array}{c}\text { Term } \\
\text { premium }\end{array}$ & N & Mean & Std Error & Minimum & Maximum \\
\hline$p_{1}$ & 447 & 0.006708 & 0.018940 & -0.058423 & 0.058187 \\
\hline$p_{2}$ & 447 & 0.004772 & 0.017172 & -0.051430 & 0.049256 \\
\hline$p_{4}$ & 447 & 0.003905 & 0.015089 & -0.044474 & 0.043905 \\
\hline$p_{6}$ & 447 & 0.003276 & 0.013769 & -0.037768 & 0.045362 \\
\hline$p_{9}$ & 447 & 0.002169 & 0.012449 & -0.034199 & 0.042995 \\
\hline
\end{tabular}

Consumption is measured by the personal consumption expenditures of American households as published monthly by the Bureau of Economic Analysis (BEA, series 2.8.3). Personal consumption expenditures cover consumption of durable goods, nondurable goods and services. Consumption expenditure in value is seasonally adjusted. Monthly data are in millions of dollars. Non-durable goods are added to services expenses over the period of January 1968January 2009; this series is adjusted to take into account the variation in population (data from Table 2.6 BEA) to obtain a per capita measure of consumption. The consumption variable used in the tests is in real value. We use the Consumer Price Index (CPI) published by the Bureau of Labor Statistics to obtain the real per capita consumption expenses. The CPI is also used to estimate inflation volatility. As instruments in the empirical test we consider other available variables: the deseasoned industrial production index published by the Bureau of Labor Statistics, the M2 monetary supply (in billions of dollars seasonally adjusted) and the S\&P500 index. We also add lagged values of the term premium. The variables $d c o n s$ and $d c p i$ are the logarithm of changes of real consumption and inflation.

A global test needs to encompass the conditional variance feature as evidenced in previous studies (for instance, Del Castillo and Fillion, 2002). We estimate the conditional variance of consumption changes in the following way: the log variation of consumption, dcons, is 
calculated over a 6-month (12-month) period. If true, the C-CAPM model should be validated for any forecast horizon. Inflation is calculated in the same way. We test a joint bivariate AR to estimate the movement of real consumption and the changes of inflation over each horizon. AR models are built with non-overlapping data. This means that the 12-month movement is regressed over the previous year's movement. The residual autocorrelation after $\operatorname{AR}(1)$ consumption filtering is not significant. A GARCH model is used for time-varying conditional variance.

We first consider a joint model $\operatorname{GARCH}(1,1)$ for the variance and a bivariate $\operatorname{AR}(1)$ for the consumption and the inflation variations. A multivariate setting implies a more complex writing with stacked vectors. The multivariate AR-GARCH model is estimated using a multivariate three-equation block of variances and covariance. A general $\operatorname{AR}(1)-G A R C H(1,1)$ model expresses as follow:

$$
\begin{aligned}
& \text { dcons }_{t, t+1}=\mu_{c i}+\rho_{c i} \cdot \text { dcons }_{t-1, t}+\varepsilon_{t+1}^{c} \\
& d^{c} i_{t, t+1}=\mu_{i}+\rho_{i} \cdot d c p i_{t-1, t}+\varepsilon_{t+1}^{i} \\
& \mathrm{H}_{t}=C^{\prime} C+A^{\prime} \mathrm{E}_{t} \mathrm{E}_{t}^{\prime} A+B^{\prime} \mathrm{H}_{t-1} B
\end{aligned}
$$

$\mathrm{H}$ : vector of variance-covariance of $d c o n s$ and $d c p i$

E: vector of residual with $\mathrm{E}_{t+1} \cong N\left(\overline{0}, \mathrm{H}_{t}\right)$

A, B and C: $3 \times 3$ symmetric arrays of parameters

Individual $\mathrm{H}_{\mathrm{t}}$ element: ${ }_{t} v_{1}^{l, k}=c^{l, k}+a^{l, k} \cdot \varepsilon_{t}^{l} \varepsilon_{t}^{k}+b^{l, k} \cdot{ }_{t-1} v_{1}^{l, k}$

Different specifications of (17) are compared. The most significant is a reduced AR(1)$\operatorname{GARCH}(0,1)$ model, i.e., a model explaining the time varying variances by past innovations and not by a one-period lag of the variance. The $b^{l, k}$ coefficient in (17) are set to zero. The coefficients of the multivariate $\operatorname{AR}(1)-\operatorname{GARCH}(0,1)$ are all significant. The $\operatorname{AR}(1)-$ $\operatorname{GARCH}(0,1)$ model is hereafter named AR-ARCH. Table 3 presents the results of the different specifications of $(17)^{6}$. Estimates of the $a^{l, k}$ coefficients are all positive and below one leading to stationary forecast for the variance. They are all significantly below one at the $1 \%$ level except for the consumption variance process for the one-year horizon (p-value: 0,93). The estimated AR-ARCH multivariate process is stationary for the 6 month horizon. The estimate in the case of a 1 year horizon is not as sound with a $a^{c, c}$ estimate of 0.9958 but not different from one. 
Table 3: Estimation of multivariate AR-ARCH consumption and inflation models

(Consumption data: monthly real personal household expenditures, seasonally adjusted, monthly data; one-year horizon 1970:04-2009:01, N: 466; 6-month horizon 1969:4-2009:1, $n=478 ; \quad A R$ part of the model is bivariate; $A R(1)$ consumption process: dcons $_{t, t+1}=\mu_{c}+\rho_{c} \cdot$ dcons $_{t-1, t}+\varepsilon_{t+1}$ where dcons is the log 12-month/6-month variation of real consumption; $A R(1)$ inflation process: $d c p i_{t, t+1}=\mu_{i}+\rho_{i} \cdot d c p i_{t-1, t}+\varepsilon_{t+1}$ where dcpi is the 12month/6-month variation of the CPI; brackets signal the time lag of 6 or 12 month; the ARCH process is: ${ }_{t} v_{1}^{l, k}=c^{l, k}+a^{l, k} \cdot \varepsilon_{t}^{l} \varepsilon_{t}^{k}$, with $\varepsilon_{t+1}^{i} \cong N\left(0,{ }_{t} v^{i}\right)$ and subscripts $l$ and $k$ for the explicative variable series; $c^{c, c}$ and $a^{c, c}$ are parameters of the consumption ARCH variance; $c^{i, i}$ and $a^{i, i}$ are the same for the inflation variance; and $c^{c, i}$ and $a^{c, i}$ are parameters of the covariance between consumption and inflation movements, White's covariance matrix adjusted for errors)

\begin{tabular}{lccc|cccc}
\hline \multicolumn{3}{c}{ 12 months time horizon } & \multicolumn{4}{c}{ 6 months time horizon } \\
\hline$\mu_{c}$ & coef & std error & p-value & & coef & std error & p-value \\
$\rho_{c}$ & 0.0183 & $1.9194 \times 10^{-3}$ & 0.00 & $\mu_{c}$ & 0.0108 & $7.4011 \times 10^{-4}$ & 0.00 \\
$\mu_{i}$ & -0.1172 & 0.0521 & 0.02 & $\rho_{c}$ & -0.1474 & 0.0638 & 0.03 \\
$\rho_{i}$ & 0.0157 & $1.7645 \times 10^{-3}$ & 0.00 & $\mu_{i}$ & 0.0108 & $1.0776 \times 10^{-3}$ & 0.00 \\
\hline$c^{c, c}$ & 0.4798 & 0.0294 & 0.00 & $\rho_{i}$ & 0.4103 & 0.0577 & 0.00 \\
$c^{c, i}$ & $2.26 \times 10^{-5}$ & $3.8971 \times 10^{-6}$ & 0.00 & $c^{c, c}$ & $2.75 \times 10^{-5}$ & $4.6196 \times 10^{-6}$ & 0.00 \\
$c^{i, i}$ & $-9.410 \times 10^{-6}$ & $2.4598 \times 10^{-6}$ & 0.00 & $c^{c, i}$ & $-1.34 \times 10^{-5}$ & $3.0939 \times 10^{-6}$ & 0.00 \\
\hline$a^{c, c}$ & $2.16 \times 10^{-5}$ & $4.9478 \times 10^{-6}$ & 0.00 & $c^{i, i}$ & $2.53 \times 10^{-5}$ & $3.1897 \times 10^{-6}$ & 0.00 \\
$a^{c, i}$ & 0.9958 & 0.0467 & 0.00 & $a^{c, c}$ & 0.7970 & 0.0662 & 0.00 \\
$a^{i, i}$ & 0.9150 & 0.0303 & 0.00 & $a^{c, i}$ & 0.7541 & 0.0506 & 0.00 \\
\hline
\end{tabular}

The unconditional autocorrelation coefficient of annual (or half-yearly) consumption variation $d$ cons is -0.1172 (-0.1474 for 6-month variations). Considering actual quarterly Canadian consumption data, Del Castillo and Fillion (2002) concluded in favor of an AR(1)-GARCH(1,1) model. They obtained a negative correlation coefficient of -0.2047 between consumption variations over the period 1961-2000. Our estimate of the autocorrelation between annual inflation movements is 0.4798 ( 0.4103 for 6-month variations).

An AR-ARCH consumption model allows us to estimate an "out-of sample" estimate of annual (semi-annual) variance over the period 1971:12-2008:01. For each period, we used new estimates of the consumption process starting from 1970:03. We have a minimum calibrating window of 22 observations. Each supplementary period is added when moving upward in the time sample. In the end, we had a maximum of 434 observations with which to estimate an "out-of sample" conditional variance. At each time $t$, the conditional variance is obtained using 
the information set effectively available at time $t$ for $t+1$. Remembering that the step for the next period is 12 (or 6) months ahead, we generate four series of out-of-sample conditional variances for the two consumption and inflation processes and for the two period horizons of 6 and 12 months ahead. Conditional out-of-sample covariances are computed using the multivariate AR-ARCH model and equation (17).

In the estimation, $v_{1}$ is the conditional variance over the monthly data from $t$ to $t+1$. We check that the conditional variance follows a stationary process. Over the global observation period, the estimated $a^{l, k}$ coefficients of the AR-ARCH model are below one. The unconditional value of the unitary variance $v_{1}$ of consumption is $c^{c, c} /\left(1-a^{c, c}\right)$, or $2.121 \times 10^{-4}$ with the estimated parameters over the whole set of observations. It is $2.895 \times 10^{-4}$ for the inflation processes. By substitutive recursions, the conditional expectation at time $t$ of a general $\operatorname{GARCH}(0,1)$ one period variance at $t+j$ is ${ }^{7}$ :

$$
E_{t}\left({ }_{t+j} v_{1}^{l, k}\right)=\left(a^{l, k}\right)^{j} \cdot\left({ }_{t} v_{1}^{l, k}-\frac{c^{l, k}}{1-a^{l, k}}\right)+\frac{c^{l, k}}{1-a^{l, k}}
$$

This gives the conditional forward variances for $i=j$ and the conditional covariance between consumption and inflation for $i=j$. The multi-period forward anticipated volatility follows a mean reverting process toward its unconditional mean (as estimated with time $t$ parameters) with a speed of $a^{l, k}$. Equation (18) is used to estimate the conditional variance of consumption expected at time $t$ for the $t+6$ or the $t+12$ time period. We used a dynamic forecast procedure with $j$ set according to the time interval to 6 or 12 months. To obtain conditional forecasts of variance based on the available information at time $t$, the ARCH parameters $c^{l, k}$ and $a^{l, k}$ and the monthly coefficients of the bivariate AR(1) processes were re-estimated for each period.

At each period the forecasted conditional covariances are calculated using equation (18) and the relevant re-estimated parameters $a^{l, k}$ and $c^{l, k}$. We estimate the multivariate AR-ARCH process for consumption/inflation over the previous sample of data and anticipated "out-of-sample" conditional volatilities over the two time horizons of 6 months and 1 year. This "out-of-sample" conditional variance recursively uses the time $t$ information set and avoids the "look-ahead bias" as identified by Brennan and Xia (2005). The corresponding out-of-sample variance variables are named in the test Vfit and Vfitcpi (Vfitcross for the covariance term). These three series are filtered to eliminate outliers. Another simpler dynamic approach of conditional variance is to take the historical covariance matrix of consumption/inflation variations at any 
time $t$ as calculated from a window of past and current observations. That window is the set of all consumption and CPI observations from 1970:03 (which gives a minimum of 22 data points and a maximum of 434). The covariance matrix gives two historical variances and one covariance term. This historical volatility Vhist for the consumption changes is an alternative predictor of the future volatility at time $t+6$ or $t+12$ if we suppose that Vhist follows a conditional random walk. Parallel variables are Vhistcpi for the historical conditional inflation variance and Vhistcross for the historical covariance. Finally, the conditional volatility of consumption was estimated over the whole set of observations over the 1970:03-2009:01 period, i.e., 466 observations. This gives a conditional volatility, albeit one estimated "insample". We can easily obtain a retrospective estimate of the consumption variance for any date t. This "in-sample" consumption variance, called Vins, is estimated using a unique parameterized value of the bivariate $\operatorname{AR}(1)$ consumption autocorrelation coefficient (for instance $\rho_{c}=0.3664$ for consumption, 12 month period). We obtain from the one time global sample AR-ARCH estimated Vinscpi and Vinscross time series of in-sample conditional inflation variance and covariance with consumption. The conditional volatility measure Vins obviously suffers from a "look-ahead bias" (Brennan and Xia, 2005). The three methods to estimate the conditional variance of future consumption changes are not equivalent from a theoretical point of view. We expect that the last measure will give poor results in the empirical test. The first two series are conditioned using the same information set effectively available to investors at each time $t$. The conditional volatility Vfit (respectively Vfitcpi and Vfitcross) is rational in the sense that it takes into account the identified stochastic processes followed by consumption and inflation. This process allows the building of a forecast of the conditional variance in the future. The historical conditional volatility Vhist (respectively Vhistcpi and Vhistcross) is a naïve approach that is conditioned by the available information set at each time. Here, the investor thinks that the consumption volatility changes randomly and that the best predictor is its most recent past observation.

Table 4-1: Descriptive statistics of consumption conditional volatility

(Consumption data: monthly personal real household expenditure, seasonally adjusted; log variation over 6- and 12-month periods during 1968:03-2009:01; Vfit: rational ex ante out-ofsample estimates of volatility conditioned using a multivariate AR-ARCH recursive process; Vhist: ex ante estimates of volatility using the historical data set available at each period; Vins: in-sample conditional volatility estimated using an AR-ARCH process estimated once over the whole period; Vfit series are filtered to eliminate outliers)

\begin{tabular}{llllll}
\hline 6 months & N & Mean & Std Error & Minimum & Maximum \\
\hline
\end{tabular}




\begin{tabular}{cccccc}
\hline Vfit & 471 & 0.000361 & 0.003261 & 0.000000 & 0.070077 \\
Vhist & 478 & 0.000201 & 0.000065 & 0.000000 & 0.000267 \\
Vins & 478 & 0.000121 & 0.000194 & 0.000000 & 0.001927 \\
\hline 12 months & $\mathbf{N}$ & Mean & Std Error & Minimum & Maximum \\
\hline Vfit & 383 & 0.000901 & 0.001178 & 0.000115 & 0.011307 \\
Vhist & 386 & 0.000679 & 0.000068 & 0.000591 & 0.000795 \\
Vins & 386 & 0.000292 & 0.000459 & 0.000023 & 0.003920 \\
\hline
\end{tabular}

Table 4-2: Descriptive statistics of inflation conditional volatility

(Inflation data: monthly consumer price index, log variation over 6- and 12-month periods during 1968:03-2009:01; Vfit: rational ex ante out-of-sample estimates of volatility conditioned using a multivariate AR-ARCH recursive process; Vhist: ex ante estimates of volatility using the historical data set available at each period; Vins: in-sample conditional volatility estimated using an AR-ARCH process estimated once over the whole period; Vfit series is filtered to eliminate outliers)

\begin{tabular}{cccccc}
\hline 6 months & N & Mean & Std Error & Minimum & Maximum \\
\hline Vfit & 471 & 0.000284 & 0.003919 & 0.000000 & 0.085101 \\
Vhist & 478 & 0.000987 & 0.000392 & 0.000000 & 0.001653 \\
Vins & 478 & 0.000130 & 0.000202 & 0.000000 & 0.001377 \\
\hline 12 months & $\mathbf{N}$ & Mean & Std Error & Minimum & Maximum \\
\hline Vfit & 383 & 0.000476 & 0.001174 & 0.000025 & 0.010832 \\
Vhist & 386 & 0.004415 & 0.001028 & 0.002910 & 0.006588 \\
Vins & 386 & 0.000327 & 0.000759 & 0.000022 & 0.004964 \\
\hline
\end{tabular}

Table 4-3: Descriptive statistics of consumption and inflation conditional covariance

(Consumption data: monthly personal household expenditures, seasonally adjusted; inflation data: monthly consumer price index, log variation over 6- and 12-month periods during 1968:03-2009:01; Vfit: rational ex ante out-of-sample estimates of volatility conditioned using an AR-ARCH moving process; Vhist: ex ante estimates of volatility using the historical data set available at each period; Vins: in-sample conditional volatility estimated using an AR-ARCH process estimated once over the whole period; Vfit series is filtered to eliminate outliers)

\begin{tabular}{cccccc}
\hline 6 months & N & Mean & Std Error & Minimum & Maximum \\
\hline Vfit & 475 & -0.000061 & 0.000165 & -0.001053 & 0.001240 \\
Vhist & 478 & 0.000120 & 0.000055 & 0.000000 & 0.000263 \\
Vins & 478 & -0.000067 & 0.000164 & -0.001482 & 0.000248 \\
\hline 12 months & & Mean & Std Error & Minimum & Maximum \\
\hline Vfit & 383 & -0.000255 & 0.001773 & -0.007060 & 0.030145 \\
Vhist & 386 & 0.000608 & 0.000136 & 0.000394 & 0.001060 \\
Vins & 386 & -0.000134 & 0.000506 & -0.003963 & 0.000450 \\
\hline
\end{tabular}

Looking at Table 4, we see that the average value of Vfit is higher than the other estimates of volatility. This measure effectively refers to the process of consumption identified during the past. It allows forecasting with better precision, i.e., a lower average volatility, using an AR- 
ARCH model. By integrating relevant information, the method allows a better fit. The model is continuously re-estimated for Vfit, although the in-sample model Vins performs a once and for all estimation of the AR-ARCH model parameters. It has a smoothing effect and the average volatility is effectively lower for Vins than for Vfit. Vins shows extreme peaks in some periods and is systematically higher during the first half of the period.

\subsection{Univariate term premium test for each maturity}

We consider separately each term premium return for bond investment with a remaining maturity of 1,2, 4, 6 and 9 years at the end of the investment period of 6 and 12 month. Equation (16) is run separately and the fit of the parsimonious C-CAPM model is estimated for each different term premium. This univariate test does not refer to the global market equilibrium resulting in a term structure of interest rates.

A simple ordinary least squares regression would entail very strong assumptions regarding the residuals. We use a GMM method to integrate information available at time $t$ for a forecast over a 6- or 12-month time horizon. As instruments, we use the industrial production lagged by $h+1$ months, the M2 money supply lagged by $\mathrm{h}+1$ months, the Standard and Poor's index (lagged by $\mathrm{h}+1$ months) and the endogenous variable itself (i.e., the term premium) lagged by $\mathrm{h}+1$ to $\mathrm{h}+5$ months. According to the time horizon, $h$ is equal to 6 or 12 months. The ex post term premium is obtained at time $t+h$. Its forecast is set $h$ months before. This means that instruments considered in the GMM are with an $h+1$-month lag because the information available at time $t$ for a decision is that of the previous period $t-1^{8}$. We add as instruments the past values of the endogenous term premiums from lag $h+1$ to lag $h+5$. Looking further into the past of the term premium does not add anything to the estimation.

Analysis of the fit of the model is developed through the J-test, the Akaike Information Criterion (AIC) and the Bayesian Schwarz Criterion (BSC). The J-statistic tests the overidentification constraint; it is compared to a chi-squared distribution ${ }^{9}$. A negligible p-value leads to the conclusion that the null hypothesis (i.e., that the cross moments equal zero, or equivalently, zero pricing errors) cannot be accepted. Globally, the eight instruments help to strongly overidentify the model. The J-test is accepted for each of the out-of-sample measures of conditional volatility but also for the historical and in-sample measures ${ }^{10}$. GMM appears relevant and instruments seem to be consistent with the estimation. 
Table 5: Univariate model estimate using different conditional variance and covariance $\underline{\text { measures }}$

(GMM estimates of linear equation (16); two time horizons $h: 6$ and 12 months, 197412:2009:1, N=410; five interest rate maturities $j$ of 1,2, 4, 6 and 9 years at the end of the forecast period; $p_{1}$ is the 1-year (resp. 2-, 4-, 6- and 9-year) term premium bias of a 1-year (resp. 2-, 4-, 6-, 9-year) remaining maturity spot interest rate compared with its forward value set at time $t$-h; instruments are industrial production monthly change lagged by $h+1$ months, M2 money supply monthly change lagged by $h+1$ month, Standard and Poor's Stock Index monthly change lagged by $h+1$ month, and the term premium itself lagged by $h+1$ to $h+5$ months; J: Hansen's J-test; number of degrees of freedom of the J-test is 4; AIC: Akaike Information Criterion, BSC: Bayesian Schwarz Criterion)

\begin{tabular}{ccccc}
\hline & \multicolumn{3}{c}{ 6-month time horizon } & \\
\hline & $\mathbf{J}$ & p-value & AIC & SBC \\
\hline$p_{1}$-Vfit & 2.87 & 0.59 & 61.18 & 77.25 \\
$p_{1}$-Vhist & 5.36 & 0.25 & 92.04 & 108.11 \\
$p_{1}$-Vins & 2.48 & 0.65 & 71.94 & 88.01 \\
$p_{2}$-Vfit & 3.17 & 0.53 & 54.85 & 70.92 \\
$p_{2}$-Vhist & 8.25 & 0.08 & 44.82 & 60.88 \\
$p_{2}$-Vins & 2.67 & 0.61 & 46.99 & 63.06 \\
$p_{4}$-Vfit & 2.51 & 0.64 & 45.13 & 61.20 \\
$p_{4}$-Vhist & 1.80 & 0.77 & 78.47 & 94.54 \\
$p_{4}$-Vins & 1.38 & 0.84 & 37.50 & 53.56 \\
$p_{6}$-Vfit & 2.40 & 0.66 & 35.33 & 51.39 \\
$p_{6}$-Vhist & 0.75 & 0.94 & 88.81 & 104.87 \\
$p_{6}$-Vins & 0.59 & 0.96 & 34.25 & 50.31 \\
$p_{9}$-Vfit & 1.58 & 0.81 & 35.21 & 51.27 \\
$p_{9}$-Vhist & 0.50 & 0.97 & 91.83 & 107.90 \\
$p_{9}$-Vins & 0.36 & 0.98 & 37.53 & 53.59 \\
\hline
\end{tabular}

12-month time horizon

\begin{tabular}{ccccc}
\hline & J & p-value & AIC & SBC \\
\hline$p_{1}$-Vfit & 3.95 & 0.41 & 152.13 & 168.20 \\
$p_{1}$-Vhist & 3.67 & 0.45 & 94.93 & 110.99 \\
$p_{1}$-Vins & 5.53 & 0.24 & 69.49 & 85.56 \\
$p_{2}$-Vfit & 2.29 & 0.68 & 102.13 & 118.19 \\
$p_{2}$-Vhist & 1.37 & 0.85 & 178.05 & 194.11 \\
$p_{2}$-Vins & 5.00 & 0.29 & 60.37 & 76.44 \\
$p_{4}$-Vfit & 0.72 & 0.95 & 93.83 & 109.89 \\
$p_{4}$-Vhist & 0.54 & 0.97 & 235.26 & 251.32 \\
$p_{4}$-Vins & 2.90 & 0.57 & 78.23 & 78.23 \\
$p_{6}$-Vfit & 0.70 & 0.95 & 95.22 & 111.28 \\
$p_{6}$-Vhist & 0.34 & 0.99 & 286.90 & 302.97 \\
$p_{6}$-Vins & 2.08 & 0.72 & 68.77 & 84.83 \\
$p_{9}$-Vfit & 0.86 & 0.93 & 107.04 & 123.10 \\
$p_{9}$-Vhist & 0.26 & 0.99 & 259.31 & 275.37 \\
$p_{9}$-Vins & 0.89 & 0.92 & 76.54 & 92.61 \\
\hline
\end{tabular}


In terms of goodness of fit, the J-values are higher for the conditional "out-of-sample" measure. Comparing "out-of-sample" measures, the best (lower) values of the information criterion AIC and SBC result unanimously from the use of the Vfit measure compared to the Vhist measure. The "in-sample" measure Vins suffers from a bias. Its estimation covers future observations not available at time t. It would logically seem to be better in terms of AIC or SBC. We decide not to look at these. The result confirms our methodology of strictly estimating the conditional volatility using only available information with a continuously updated process.

The individual GMM univariate estimates give mitigated results for the coefficient estimates (see Appendix B). A lot of them are statistically significant and positive when we consider as explanatory variances the out-of-sample variances and covariance in equation (16). These results are in line with those of Del Castillo and Fillion (2002), who also found a positive and significant univariate relationship between the term premium and the conditional variance in Canadian data. The specification using the conditional "in-sample" variance, Vins, and the historical variance, Vhist, are clearly not supported. Univariate regressions appear very poor, with no significant coefficients. Ex post estimates of volatility processes suffer from a selfselection bias and give no results. The sign of relationships (16) seems to support that the term premium, which is implicit in the term structure, is positively linked with the conditional variance of the consumption process. It highlights the fact that testing of the C-CAPM model should be carried out with conditional variance forecasts oriented toward the future. Using the conditional "in-sample" variances as the explanatory variable in a simple univariate test is highly questionable and would lead to incorrect conclusions.

\subsection{Multivariate global term premiums test}

A multivariate test considers globally the five different term premiums. It is performed twice over the two time horizons. A GMM estimate with the same instruments as above is used. The previous test was carried out to examine univariate relationships; we consider each term premium series separately. This test ignores the fact that the term structure of interest rates is a global and coherent set of data. We need to look at the five time series of term premiums from 1 to 9 years as a set of five equations to estimate them jointly. We test the following systems first rewriting the unrestricted equation (15') of the parsimonious C-CAPM model: 


$$
\begin{aligned}
& p_{j-1}=k_{j}^{0}-\frac{\alpha^{2}}{2 \cdot(j-1)}\left[\left(\frac{\left(1-\rho_{c}^{j}\right)^{2}}{\left(1-\rho_{c}\right)^{2}}-1\right)\right] . \text { Vfit }-\frac{1}{2 \cdot(j-1)}\left[\left(\frac{\left(1-\rho_{i}^{j}\right)^{2}}{\left(1-\rho_{i}\right)^{2}}-1\right)\right] . \text { Vfitcpi } \\
& -\frac{\alpha}{(j-1)}\left[\left(\frac{\left(1-\rho_{c}^{j}\right)}{\left(1-\rho_{c}\right)}\right)\left(\frac{\left(1-\rho_{i}^{j}\right)}{\left(1-\rho_{i}\right)}\right)-1\right] . \text { Vfitcross }
\end{aligned}
$$

where $p$ is the term premium, $k^{0}$ a constant that captures the non linear time preference, Vfit is the look-ahead consumption volatility, Vfitcpi is the look-ahead inflation volatility and Vfitcross is the look-ahead correlation between consumption and inflation.

The multivariate non-linear system with five constant terms should be null with a standard constant subjective discount rate, $\delta$. The variables $k_{j}^{0}$ stand for the constants $(j=1,2,4,6$ and 9). $\alpha$ corresponds to the risk aversion coefficient. The coefficients $\rho_{c}$ and $\rho_{i}$ are unconditional estimates of the AR process for consumption and inflation, respectively. A restricted form of (19) is a multivariate nonlinear system of five term premiums with equal constant terms $k_{1}^{0}=k_{2}^{0}=\ldots=k_{9}^{0}=k_{c}^{0}$ called restricted model I. A more restricted form is tested with no constant (i.e., $k_{j}^{0}=0$ for any $j$ ) called restricted form II. The latter corresponds to the standard C-CAPM model with a constant subjective time discount factor.

As instruments, we focus on the Standard and Poor's Stock Index monthly variations lagged from $h+1$ to $h+3$ periods. Globally, the three instruments per equation (i.e., 15 for the multivariate system) help to overidentify the residuals of the model. The J-test is accepted for the out-of-sample measures of conditional volatility looking at both the 6-month and the 12month horizons. This means that the instruments are orthogonal with residuals and helps to infer statistically the significance and the values of the estimated coefficients.

Table 6: Multivariate nonlinear estimates

(Multivariate GMM estimate of five simultaneous equations (19) using the term premiums $p_{1}$, $p_{2}, p_{4}, p_{6}$ and $p_{9}$ as endogenous variables; two time horizons: 6 months and 12 months; $p$ : term premium, i.e., forward 6-month (and 12 month) interest rates of 1, 2, 4, 6 and 9 years minus corresponding realized spot rates 6 months later; explanatory variables are the rational ex ante out-of-sample estimates of consumption and inflation variances Vfit and Vfitcpi and covariances, Vfitcross; Vfit: rational ex ante out-of-sample estimates of consumption volatility conditioned using a multivariate AR-ARCH model; Vfitcpi: rational ex ante out-of-sample estimates of inflation volatility conditioned using a multivariate AR-ARCH model; Vfitcross: rational ex ante out-of-sample estimates of covariance between consumption and inflation conditioned using a multivariate AR-ARCH model; instruments are $S \& P 500$ index changes with a 1 to 3 month lag; $k^{0}$ : constant estimate; $p\left(k^{0}\right)$ : significance level for the constant 
estimate; $\alpha$ : risk aversion estimate; $p(\alpha)$ : significance level for the parameter of conditional volatility; $J$ : Hansen's $J$-test of restrictions from the specification of instruments; $p(J)$ : significance level of the specification test of the instruments; 1974:12-2009:01; N=410)

\begin{tabular}{|c|c|c|c|c|c|c|c|}
\hline \multicolumn{8}{|c|}{6 months } \\
\hline Unrestricted & $k_{1}^{0}$ & $k_{2}^{0}$ & $k_{4}^{0}$ & $k_{6}^{0}$ & $k_{9}^{0}$ & $\alpha$ & $\mathbf{J}$ \\
\hline coefficient & -0.0007 & 0.0009 & 0.0013 & 0.0011 & 0.0007 & -9.1655 & 3.82 \\
\hline (p-value) & $(0.89)$ & $(0.80)$ & $(0.58)$ & $(0.59)$ & $(0.70)$ & $(0.47)$ & $(0.92)$ \\
\hline Restricted I & $k_{c}^{0}$ & & & & & $\alpha$ & $\mathbf{J}$ \\
\hline coefficient & -0.0001 & & & & & 6.2433 & 13.51 \\
\hline (p-value) & $(0.94)$ & & & & & $(0.08)$ & $(0.41)$ \\
\hline Restricted II & & & & & & $\alpha$ & $\mathbf{J}$ \\
\hline coefficient & & & & & & 6.1893 & 13.51 \\
\hline (p-value) & & & & & & $(0.08)$ & $(0.49)$ \\
\hline \multicolumn{8}{|c|}{12 months } \\
\hline Unrestricted & $k_{1}^{0}$ & $k_{2}^{0}$ & $k_{4}^{0}$ & $k_{6}^{0}$ & $k_{9}^{0}$ & $\alpha$ & $\mathbf{J}$ \\
\hline coefficient & 0.0030 & 0.0013 & 0.0009 & 0.0007 & 0.0001 & -3.0635 & 2.66 \\
\hline (p-value) & $(0.45)$ & $(0.70)$ & $(0.77)$ & $(0.80)$ & $(0.97)$ & $(0.44)$ & $(0.98)$ \\
\hline Restricted I & $k_{c}^{0}$ & & & & & $\alpha$ & $\mathbf{J}$ \\
\hline coefficient & -0.0018 & & & & & 5.9480 & 8.09 \\
\hline (p-value) & $(0.40)$ & & & & & $(0.00)$ & $(0.84)$ \\
\hline Restricted II & & & & & & $\alpha$ & $\mathbf{J}$ \\
\hline coefficient & & & & & & 5.9181 & 8.51 \\
\hline (p-value) & & & & & & $(0.00)$ & $(0.86)$ \\
\hline
\end{tabular}

In the unrestricted model, none of the parameter estimates are significant for both time horizons. The different constant terms $k_{j}^{0}$ are not significant nor is the risk coefficient, although the model seems correctly specified with good instruments. The unrestricted model should be disregarded.

The restricted form I using instruments gives a null coefficient $k_{c}^{0}$ and significantly positive $\alpha$ coefficient. The restricted form II confirms this result. The restricted models I and II give significant risk aversion estimates around 6. The standard C-CAPM restricted model is confirmed. Estimates of the risk aversion parameter are coherent with what is expected in the literature (Mehra and Prescott, 1985; Weil, 1989). If we consider as normal risk aversion coefficients around 2 to 3 , the interest rate puzzle is attenuated and partially solved. 
We also test a linear multivariate SUR model of the term premiums. This specification is independent of the unconditional input in the previous nonlinear test where coefficients $\rho_{c}$ and $\rho_{i}$ in equation (19) have values coming from a global estimate over the whole sample (see Table $3)^{11}$. To obtain estimates of the coefficients free of this assumption, we use a linear model. The SUR allows us to take into account cross-correlations between term premiums of different maturities ${ }^{12}$. We estimate the multivariate unrestricted linear form of equation (15'):

$$
\bar{p}=\bar{k}^{0}+\bar{K} \cdot \bar{V}+\bar{\eta}
$$

where $\bar{p}$ is a vector of five time series corresponding to the maturities $j=1,2,5,6,9$ years. $\bar{V}$ is the conditional "out-of-sample" variance-covariance matrix. The vector $\bar{k}^{0}$ and the array $\bar{K}$ are respectively the constant and coefficients that are jointly estimated. Significant $k_{j}^{0}$ coefficients would support the hypothesis of a non-constant psychological price of time. A test of a restricted version of the multivariate linear model (20) is carried out by constraining the value of the coefficient $k_{j}^{0}$ to be unchanged between all $j$ maturities (Restricted I). This restricted specification corresponds to equation (16), with a supplementary restriction on the term structure of the psychological price of time $\delta(j)$. We also test a more restricted model without any constant term (Restricted II). We consider:

$$
\begin{aligned}
& \bar{p}=\bar{k}_{c}^{0}+\bar{K} \cdot \bar{V}+\bar{\eta}, \text { with } k_{j}^{0} \text { constant for any } \mathrm{j} \\
& \bar{p}=\bar{K} \cdot \bar{V}+\bar{\eta}
\end{aligned}
$$

Table 7: Multivariate linear estimates - Test of model restrictions

(Likelihood ratio test; SUR linear multivariate estimates; 1974:12-2009:01; N=410; models are from the less constrained equation (20a) with five different values for the constant, the restricted multivariate model I with the same constant shared between the five equations (20b) and the most constrained equations system II (20c) with no constant; two time horizons: 6 months and 12 months; endogenous variables are term premiums, i.e., forward 6-month (and 12-month) interest rates of 1, 2, 4, 6 and 9 years minus corresponding realized spot rates 6 months later; explanatory variables are the rational ex ante out-of-sample estimates of consumption and inflation variances Vfit and Vfitcpi and covariances, Vfitcross; Vfit: rational ex ante out-of-sample estimates of consumption volatility conditioned using a multivariate ARARCH model; Vfitcpi: rational ex ante out-of-sample estimates of inflation volatility conditioned using a multivariate AR-ARCH model; Vfitcross: rational ex ante out-of-sample estimates of covariance between consumption and inflation conditioned using a multivariate AR-ARCH model; Logdet: logarithm of the determinant of the residual matrix; Likelihood 
ratio: value of the likelihood ratio; p-value: probability statistic associated with the likelihood ratio with a number of degrees of freedom equal to the number of restrictions)

\begin{tabular}{ccccc}
\hline 12-month horizon & Logdet 1 $^{\text {st }}$ eq. & Logdet 2 $^{\text {nd }}$ eq. & Likelihood Ratio & p-value \\
\hline $\begin{array}{c}\text { Unrestricted vs. } \\
\text { Restricted I (4 df). } \\
\text { Restricted I vs. }\end{array}$ & -58.93 & -58.36 & 231.32 & 0.00 \\
$\begin{array}{c}\text { restricted II (1 df) } \\
\text { Unrestricted vs. } \\
\text { restricted II }\end{array}$ & -58.36 & -58.37 & 4.27 & 0.04 \\
\hline 6-month horizon & -58.93 & -58.37 & 222.53 & 0.00 \\
\hline $\begin{array}{c}\text { Unrestricted vs. } \\
\text { Restricted I (4 df). } \\
\text { Restricted I vs. }\end{array}$ & -62.43 & Logdet 2 $^{\text {nd }}$ eq. & Likelihood Ratio & p-value \\
restricted II (1 df) & -62.27 & -62.27 & 64.56 & 0.00 \\
$\quad \begin{array}{l}\text { Unrestricted vs. } \\
\text { restricted II }\end{array}$ & -62.43 & -62.26 & 6.60 & 0.01 \\
\hline
\end{tabular}

The likelihood ratio test between the three specifications is calculated for the two time horizons (see Table 7). The unrestricted nonlinear model is significantly different from the two restricted forms I and II. This confirms the non reliance of a decreasing time preference model already seen Table 6 . The two restricted models do not appear significantly different at $1 \%$ level. It is strictly in line with the previous results showing a null constant. This confirms the significance of the specification without any constant and the rejection of the non-standard consumptioninvestment model ${ }^{13}$.

We privilege the SUR model without a constant because the less restricted forms with possible different subjective discount rates are not supported in the previous test. The standard setting with a flat discount rate yields a three-variable linear model of the explicatives, Vfit, Vfitcpi and Vfitcross. Results are presented in Tables 8 and 9 for the two time horizons.

Table 8: Multivariate linear SUR estimate 6-month horizon

(Multivariate estimate of five simultaneous equations (20c); Seemingly Unrelated Regressions without instruments; endogenous variables are term premiums, i.e., forward 6-month (and 12 month) interest rates of 1, 2, 4, 6 and 9 years minus corresponding realized spot rates 6 months later; explanatory variables are the rational ex ante out-of-sample estimates of consumption and inflation variances Vfit and Vfitcpi and covariances, Vfitcross; Vfit: rational ex ante out-ofsample estimates of consumption volatility conditioned using a bivariate AR-ARCH model; Vfitcpi: rational ex ante out-of-sample estimates of inflation volatility conditioned using a bivariate AR-ARCH model; Vfitcross: rational ex ante out-of-sample estimates of covariance between consumption and inflation conditioned using a bivariate AR-ARCH model; $k^{0}$ : regression coefficient estimates; $p\left(k^{0}\right)$ : p-value of the parameter of conditional volatility; 1971:01-2009:01; $N=410$ ) 


\begin{tabular}{cccc}
\hline $\begin{array}{c}\text { Term } \\
\text { premium } \\
\text { maturity }\end{array}$ & $\begin{array}{c}k_{1}^{0} \\
\text { (p-value) }\end{array}$ & $\begin{array}{c}k_{2}^{0} \\
\text { (p-value) }\end{array}$ & $\begin{array}{c}k_{3}^{0} \\
\text { (p-value) }\end{array}$ \\
\hline$p_{1}$ & 46.1133 & 19.8384 & 102.6817 \\
& $(0.00)$ & $(0.01)$ & $(0.00)$ \\
$p_{2}$ & 38.1338 & 12.1475 & 83.3747 \\
& $(0.00)$ & $(0.07)$ & $(0.00)$ \\
$p_{4}$ & 30.5153 & 8.4276 & 67.1689 \\
& $(0.00)$ & $(0.17)$ & $(0.00)$ \\
$p_{6}$ & 26.2914 & 5.0623 & 56.6168 \\
& $(0.00)$ & $(0.36)$ & $(0.00)$ \\
$p_{9}$ & 22.1162 & 1.1577 & 45.9845 \\
& $(0.00)$ & $(0.82)$ & $(0.00)$ \\
\hline
\end{tabular}

Table 9: Multivariate linear SUR estimate 12-month horizon

(see Table $8 ; N=410$ )

\begin{tabular}{cccc}
\hline $\begin{array}{c}\text { Term } \\
\text { premium } \\
\text { maturity }\end{array}$ & $\begin{array}{c}k_{1}^{0} \\
\text { (p-value) }\end{array}$ & $\begin{array}{c}k_{2}^{0} \\
\text { (p-value) }\end{array}$ & $\begin{array}{c}k_{3}^{0} \\
\text { (p-value) }\end{array}$ \\
\hline$p_{1}$ & 3.7658 & -1.7311 & 1.0188 \\
& $(0.00)$ & $(0.05)$ & $(0.10)$ \\
$p_{2}$ & 2.5717 & -1.6775 & 0.8947 \\
& $(0.00)$ & $(0.03)$ & $(0.10)$ \\
$p_{4}$ & 2.0205 & -1.8040 & 0.8573 \\
& $(0.00)$ & $(0.01)$ & $(0.07)$ \\
$p_{6}$ & 1.7576 & -1.9212 & 0.7874 \\
& $(0.00)$ & $(0.00)$ & $(0.07)$ \\
$p_{9}$ & 1.3648 & -1.8730 & 0.6799 \\
& $(0.01)$ & $(0.00)$ & $(0.08)$ \\
\hline
\end{tabular}

The multivariate system (20c) using the ex ante conditional measure leads to positive risk premiums for the consumption volatility (at the 6-month horizon at the $10 \%$ level). A larger term premium is expected by investors when the consumption volatility is expected to be larger. This is in line with the intuition; however, the size of the term premium is not the same according to the maturity of the interest rates. Proportionally, the term premium for short-term bonds is more sensitive to a shock in consumption volatility than the term premium of a longterm bond. The inflation premium seems to negatively influence the term premium at the 12month horizon and is not significant at the 6-month horizon. However, the covariance risk premium is always significantly positive. It is priced according to the C-CAPM model. Globally, the conditional consumption and inflation variances and covariance are significant drivers of interest rate term premiums. 


\section{Conclusion}

The C-CAPM model gives strong theoretical support to a relationship between the uncertain process followed by consumption (and inflation) and the real expected return of assets. Looking at term premiums allows the testing of a parsimonious equilibrium model. The difficulty is mainly methodological: we need to consider the ex ante conditional volatility of consumption in the same way as the investor decides on his inter-temporal allocation. We need estimates of conditional volatilities based on the available information at the decision time. Historical ex post measures are not supported by the empirical tests. An ex ante conditional measure of consumption and inflation variance is developed using a multivariate AR-ARCH model. In the empirical test, this measure is used concurrently with two other estimates of conditional volatility: one is a naive ex ante predictor built using historical volatilities, and the other is a conditional "in-sample" ex post measure. This in-sample measure suffers from a "look-ahead bias". Our "out-of-sample" conditional volatility gives better results. Empirical testing on American bond data supports a significant positive relationship between the term premium and the conditional consumption volatility as forecasted by investors. Our results are in line with Campbell and Cochrane (2000) outlining that asset pricing models taking into account timevarying conditioning information are likely to perform better than models that do not do so. We consider a multivariate model of the term structure of interest rates that confirms the rejection of non flat subjective discount rate. Our results are in line with the traditional assumption of a constant and unique subjective discount rate for the representative agent. Moreover, the agent's risk aversion coefficient shows estimated values around 6. This means that the interest rate puzzle is largely attenuated and may be due to imperfect estimates of the conditional consumption and inflation volatilities.

\section{Appendix A: Expression of the consumption and inflation variances.}

First, we assume that the changes in consumption and inflation are IID $\left(\sigma_{t, t+1}^{2}=\ldots=\sigma_{t+j, t+j+1}^{2}=\sigma_{1}^{2}\right)$. Looking at a $j$ period horizon, we have $\sigma_{t, t+j}^{2}=j \cdot \sigma_{1}^{2}$ and the (RHS) of the term premium equation (11) becomes null. Therefore, we obtain the conclusion of the Pure Expectations Hypothesis, which states that no reward is given to forecast future spot 
interest rates from forward rates. The agents globally have a fair enough forecast of the average movement of the state variables that are risky in the economy (i.e., consumption and inflation). This becomes complex if we abandon the IID hypothesis: the risk comes from variable conditional variances and covariance. Even if the investor knows the conditional variance (covariance) at time $t$, he can only forecast the value he will face at time $t+1$.

We now assume that one-period changes in consumption are still identically distributed but no longer independent. We refer to the bivariate AR(1) stationary process ruling consumption and inflation as stated by equation (12) of the text, with $\rho$ : correlation coefficient of the variations in consumption (inflation) between any two successive periods. The term premium can easily be derived for a maturity loan of $j=2$ periods. The variance of consumption changes over a twoperiod horizon is calculated at time $\mathrm{t}$ by using ${\sigma^{2}}_{1}^{c}$. The variance is still assumed to be constant over the forward next period horizon, at any time $t$ :

$$
\begin{aligned}
& { }_{t} \sigma_{t, t+2}^{2^{c}}=\sigma^{2}\left(\Delta c_{t, t+1}+\Delta c_{t+1, t+2}\right)=\sigma_{1}^{2^{c}}+\left(1+\rho_{c}^{2}\right) \cdot \sigma_{1}^{2^{c}}+2 \cdot \operatorname{cov}\left(\Delta c_{t, t+1}, \Delta c_{t+1, t+2}\right) \\
& =\sigma_{1}^{2^{c}}+\left(1+\rho_{c}^{2}\right) \cdot \sigma_{1}^{2^{c}}+2 \cdot \rho_{c}^{2} \cdot \sigma_{1}^{2^{c}}=\left(\left(1+\rho_{c}\right)^{2}+1\right) \cdot \sigma_{1}^{2^{c}}
\end{aligned}
$$

We use a similar transformation for the time varying inflation process and the covariance. If we set $j=2$ in equation (11) and using (A.1), the terms between brackets simplify:

$$
\begin{aligned}
& E_{t}\left({ }_{t+1} p_{1}\right)=-\frac{1}{(2-1)} \frac{\alpha^{2}}{2}\left[\left(\left(1+\rho_{c}\right)^{2}+1\right) \cdot \sigma_{1}^{2^{c}}-\left(1+\rho_{c}^{2}\right) \cdot{\sigma^{2 c}}_{1}-\sigma^{2_{1}^{c}}\right] \\
& -\frac{1}{(2-1)} \frac{1}{2}\left[\left(\left(1+\rho_{i}\right)^{2}+1\right) \cdot \sigma^{2^{i}}-\left(1+\rho_{i}^{2}\right) \cdot \sigma^{2^{i}}-\sigma_{1}^{2^{i}}\right] \\
& -\frac{\alpha}{(2-1)}\left[\left(\left(1+\rho_{i}\right)\left(1+\rho_{c}\right)+1\right) \cdot \sigma_{1}^{i c}-\left(1+\rho_{i} \cdot \rho_{c}\right) \cdot \sigma_{1}^{i c}-\sigma_{1}^{i c}\right] \\
& =-\alpha^{2}\left[\sigma_{1}^{2^{c}} . \rho_{c}\right]-\left[\sigma^{2_{1}^{i}} . \rho_{i}\right]-\alpha\left[\sigma_{1}^{i c}\left(\rho_{c}+\rho_{i}\right)\right]
\end{aligned}
$$

Here, the homoscedastic term premium appears either positive or negative according to the signs of the autocorrelation coefficients. More importantly, the term premium is constant at any time $t$, which would be an assumption not compatible with time varying term premiums in the theoretical model. 
So we have to consider more general cases of conditional variance of consumption (or inflation) changes, where the variance is not constant through time. $\sigma_{t, t+1}^{2} \neq \ldots \neq \sigma_{t+j, t+j+1}^{2}$. For a time horizon of $j$ periods ahead considered at time $t$ :

$$
\begin{aligned}
& { }_{t} \sigma_{t, t+j}^{2^{c}}=E_{t}\left\{\left[\Delta c_{t, t+j}-E_{t}\left(\Delta c_{t, t+j}\right)\right]^{2}\right\} \\
& =E_{t}\left\{\left[\Delta c_{t, t+1}+\Delta c_{t+1, t+2}+\ldots+\Delta c_{t+j-1, t+j}-E_{t}\left(\Delta c_{t, t+1}+\Delta c_{t+1, t+2}+\ldots+\Delta c_{t+j-1, t+j}\right)\right]^{2}\right\} \\
& \left.=E_{t}\left\{\left[\left(1+\rho_{c}+\ldots+\rho_{c}^{j-1}\right) \cdot \varepsilon_{t+1}^{c}+\left(1+\rho_{c}+\ldots+\rho_{c}^{j-2}\right) \varepsilon_{t+2}^{c}+\ldots+\varepsilon_{t+j}^{c}\right)\right]^{2}\right\} \\
& =\left(1+\rho_{c}+\ldots+\rho_{c}^{j-1}\right)^{2}{ }_{\cdot} v_{1}^{c}+\left(1+\rho_{c}+\ldots+\rho_{c}^{j-2}\right)^{2} \cdot_{t} v_{2}^{c}+\ldots+{ }_{t} v_{j}^{c}
\end{aligned}
$$

This is equation (14) in the text. The expectation of the crossed product $\varepsilon_{k} \varepsilon_{i}$ is zero for any $k$ different from $i$. That result is also used to estimate, at time $t$, the expected variance over the period $t+1, t+j$.

$$
\begin{aligned}
& { }_{t} \sigma_{t+1, t+j}^{2^{c}}=E_{t} E_{t+1}\left\{\left[\Delta c_{t+1, t+j}-E_{t+1}\left(\Delta c_{t+1, t+j}\right)\right]^{2}\right\} \\
& =E_{t}\left\{\left[\Delta c_{t+1, t+2}+\Delta c_{t+2, t+3}+\ldots+\Delta c_{t+j-1, t+j}-E_{t+1}\left(\Delta c_{t+1, t+2}+\Delta c_{t+2, t+3}+\ldots+\Delta c_{t+j-1, t+j}\right)\right]^{2}\right\} \\
& \left.=E_{t}\left\{\left[\left(1+\rho_{c}+\ldots+\rho_{c}^{j-2}\right) \varepsilon_{t+2}^{c}+\ldots+\varepsilon_{t+j}^{c}\right)\right]^{2}\right\} \\
& =\left(1+\rho_{c}+\ldots+\rho_{c}^{j-2}\right)^{2}{ }_{t} v_{2}^{c}+\ldots+{ }_{t} v_{j}^{c}
\end{aligned}
$$

Appendix B: Parameter estimates of the univariate model using different conditional variance and covariance measures

(GMM estimates of linear equation (16); two time horizons $h: 6$ and 12 months, 197412:2009:1, N=410; five interest rate maturities $j$ of 1, 2, 4, 6 and 9 years at the end of the forecast period; $p_{1}$ is the 1-year (resp. 2-, 4-, 6- and 9-year) term premium bias of a 1-year (resp. 2-, 4-, 6-, 9-year) remaining maturity spot interest rate compared with its forward value set at time $t-h ; k^{0}$ is the regression constant; $k^{1}$ is the coefficient of the consumption conditional volatility; $k^{2}$ is the coefficient of the inflation conditional variance; $k^{3}$ is the coefficient of the consumption-inflation covariance; Vfit: rational ex ante out-of-sample estimates of volatility conditioned using a multivariate AR-ARCH recursive process; Vhist: ex ante estimates of volatility using the historical data set available at each period; Vins: in-sample conditional volatility estimated using an AR-ARCH process estimated once over the whole period; instruments are industrial production monthly change lagged by $h+1$ months, M2 money supply monthly change lagged by $h+1$ month. Standard and Poor's Stock Index monthly change lagged by $h+1$ month, and the term premium itself lagged by $h+1$ to $h+5$ months; standard errors are between brackets; ***,**,*: significant at respectively the $1 \%, 5 \%$ and $10 \%$ level)

\section{6-month time horizon}

\begin{tabular}{ccccc}
\hline Coefficients & $k_{j}^{0}$ & $k_{j}^{1}$ & $k_{j}^{2}$ & $k_{j}^{3}$ \\
\hline$p_{I^{-} \text {-Vfit }}$ & -0.0049 & $153.7738^{* *}$ & 68.4381 & $340.8336^{* * *}$
\end{tabular}




\begin{tabular}{|c|c|c|c|c|}
\hline & $(0.0060)$ & $(60.3665)$ & $(58.7720)$ & $(128.1402)$ \\
\hline \multirow[t]{2}{*}{$p_{1}$-Vhist } & -0.1475 & 533.3444 & 31.7259 & -16.5393 \\
\hline & $(0.2813)$ & (787.8103) & (79.7976) & (219.1574) \\
\hline \multirow{2}{*}{$p_{1}$-Vins } & -0.0013 & 33.3265 & $80.1916^{*}$ & $146.6088 * *$ \\
\hline & 0.0051 & $(85.83)$ & (48.3376) & (73.84) \\
\hline \multirow{2}{*}{$p_{2}-V f i t$} & -0.0050 & $142.5895 * *$ & 54.1113 & $309.0722 * *$ \\
\hline & $(0.0063)$ & $(68.1403)$ & $(65.6863)$ & $(146.6543)$ \\
\hline \multirow[t]{2}{*}{$p_{2}$-Vhist } & 0.0719 & -88.4337 & -28.4631 & -135.4311 \\
\hline & $(0.1868)$ & (580.2183) & (48.6208) & $(100.5033)$ \\
\hline \multirow[t]{2}{*}{$p_{2}$-Vins } & -0.0014 & 63.5585 & 35.1669 & $132.0169 * *$ \\
\hline & $(0.0036)$ & (66.1895) & $(38.1841)$ & $(54.6951)$ \\
\hline \multirow[t]{2}{*}{$p_{4^{-}}$Vfit } & -0.0036 & 122.9419 & 29.9548 & 255.5221 \\
\hline & $(0.0061)$ & (75.3710) & (63.7786) & (155.3831) \\
\hline \multirow[t]{2}{*}{$p_{4}$-Vhist } & 0.1410 & -346.3030 & -43.7296 & -101.0378 \\
\hline & $(0.2317)$ & (774.4615) & (55.9591) & $(128.7022)$ \\
\hline \multirow[t]{2}{*}{$p_{4^{-} \text {Vins }}$} & 0.0001 & 64.4846 & 3.7828 & $103.8245^{* *}$ \\
\hline & $(0.0029)$ & (54.7799) & (33.65) & $(47.5643)$ \\
\hline \multirow[t]{2}{*}{$p_{6}-V f i t$} & -0.001758 & 98.5286 & 4.4427 & 191.0023 \\
\hline & $(0.0055)$ & (71.4497) & $(60.2398)$ & (146.5954) \\
\hline \multirow[t]{2}{*}{$p_{\sigma^{-}}$Vhist } & 0.1577 & -417.9790 & -46.3073 & -88.0590 \\
\hline & $(0.2507)$ & (842.1253) & (59.0727) & $(147.1405)$ \\
\hline \multirow[t]{2}{*}{$p_{6}$-Vins } & 0.0012 & 61.1601 & -13.4001 & $85.1488 *$ \\
\hline & $(0.0027)$ & $(50.8834)$ & (34.0116) & (44.8206) \\
\hline \multirow[t]{2}{*}{$p_{9}-V f i t$} & -0.0028 & 105.2312 & -0.9557 & 194.7079 \\
\hline & $(0.0058)$ & (78.5986) & (64.4367) & $(162.7832)$ \\
\hline \multirow[t]{2}{*}{$p_{9}$-Vhist } & 0.1679 & -468.8285 & -45.4146 & -94.4910 \\
\hline & $(0.2623)$ & (878.7929) & (61.0494) & $(158.9661)$ \\
\hline \multirow[t]{2}{*}{$p_{9}$-Vins } & 0.0026 & 63.8221 & -42.2559 & 62.7831 \\
\hline & $(0.0027)$ & $(60.2143)$ & $(43.3581)$ & $(50.1627)$ \\
\hline
\end{tabular}

12-month time horizon

\begin{tabular}{ccccc}
\hline Coefficients & $k_{j}^{0}$ & $k_{j}^{1}$ & $k_{j}^{2}$ & $k_{j}^{3}$ \\
\hline$p_{1}$-Vfit & 0.0069 & 8.4217 & -16.7833 & -8.5810 \\
& $(0.0055)$ & $(9.6178)$ & $(14.0059)$ & $(10.5599)$ \\
$p_{1}$-Vhist & 0.1316 & -73.3320 & -8.2299 & -62.5271 \\
& $(0.4115)$ & $(376.4354)$ & $(32.9216)$ & $(45.2731)$ \\
$p_{1}$-Vins & 0.0071 & 24.8573 & -16.7167 & 3.4147 \\
& $(0.0114)$ & $(49.4223)$ & $(15.9341)$ & $(41.7113)$ \\
$p_{2}$-Vfit & 0.0051 & 5.2402 & -11.1672 & -6.9042 \\
& $(0.0044)$ & $(7.2722)$ & $(10.3466)$ & $(8.0655)$ \\
$p_{2}$-Vhist & 0.2330 & -246.8399 & -12.0837 & -12.3575 \\
& $(0.4887)$ & $(530.1302)$ & $(35.4271)$ & $(41.2788)$ \\
$p_{2}$-Vins & 0.0042 & 18.9743 & -11.9560 & -0.8306 \\
& $(0.0101)$ & $(43.4823)$ & $(14.9796)$ & $(38.2586)$ \\
$p_{4}$-Vfit & 0.0036 & 5.5536 & -10.9140 & -7.2320 \\
& $(0.0041)$ & $(6.7334)$ & $(8.7814)$ & $(6.6498)$ \\
$p_{4}$-Vhist & 0.2791 & -367.2879 & -12.0277 & 43.7914 \\
& $(0.5461)$ & $(668.0003)$ & $(34.6735)$ & $(88.9574)$
\end{tabular}




\begin{tabular}{lcccc}
$p_{4}$-Vins & -0.0005 & 25.5438 & -2.9142 & 8.5318 \\
& $(0.0093)$ & $(41.1101)$ & $(15.2260)$ & $(38.1606)$ \\
$p_{6}$-Vfit & 0.0015 & 7.7763 & -12.1160 & -7.1218 \\
& $(0.0038)$ & $(6.4191)$ & $(8.5358)$ & $(6.2567)$ \\
$p_{6}$-Vhist & 0.3171 & -440.2360 & -12.5064 & 64.7360 \\
& $(0.6058)$ & $(759.9633)$ & $(36.8837)$ & $(112.1022)$ \\
$p_{6}$-Vins & -0.0043 & 36.8340 & 0.3259 & 18.4979 \\
& $(0.0091)$ & $(40.5348)$ & $(16.0479)$ & $(40.4504)$ \\
$p_{9}$-Vfit & 0.0006 & 7.0683 & -12.5768 & -9.2680 \\
& $(0.0041)$ & $(6.2403)$ & $(8.8964)$ & $(8.2397)$ \\
$p_{9}$-Vhist & 0.2997 & -454.5993 & -9.1000 & 83.0499 \\
& $(0.5839)$ & $(758.3660)$ & $(33.3732)$ & $(122.8795)$ \\
$p_{9}$-Vins & -0.0080 & 43.3024 & 4.7124 & 24.7542 \\
& $(0.0091)$ & $(39.4611)$ & $(17.2035)$ & $(42.7464)$ \\
\hline
\end{tabular}

\section{$\underline{\text { References }}$}

Ang A. and Piazzesi M. (2003), "A no-arbitrage vector auto-regression of term structure dynamics with macro-economic and latent variables", Journal of Monetary Economics, 50, 745-787.

Ang, A., Piazzesi M. and Wei M. (2005), "What Does the Yield Curve Tell us about GDP Growth?", Journal of Econometrics, 131, 359-403.

Backus D., Foresi S., Mozumdar A. and Wu L. (2001), "Predictable changes in yields and forward rates", Journal of Financial Economics, 59, 281-311.

Backus D., Gregory A. and Zin S. (1989), "Risk premiums in the term structure: Evidence from artificial economies", Journal of Monetary Economics, 24, 371-399.

Balfoussia C. and Wickens M. (2004), "Macroeconomic sources of risk in the term structure", CESifo, Working Paper ${ }^{\circ} 1329$, University of York.

Brand M. and Wang K. (2003) "Time-Varying Risk Aversion and Unexpected Inflation,"

Journal of Monetary Economics, 50, 1457-1498.

Breeden D. (1979), “An intertemporal asset pricing model with stochastic consumption and investment opportunities”, Journal of Financial Economics, 7, 265-296.

Breeden D. (1986), "Consumption, production, inflation and interest rates", Journal of Financial Economics, 16, 3-29.

Brennan M. and Xia Y. (2005), “Tay's as good as cay's”, Finance Research Letters 2, 1-15.

Campbell J. (1986), "Bond and stock returns in a simple exchange model", Quarterly Journal of Economics, 101, 786-803.

Campbell J., and Cochrane J. (1999), "By force of habit: A consumption-based explanation of aggregate stock market behavior”, Journal of Political Economy, 107, 205-251

Campbell J. and Cochrane J. (2000), "Explaining the poor performance of consumption-based asset pricing models", Journal of Finance, 55, 2863-2878.

Campbell J., Lo A. and MacKinlay C. (1997), "The Econometrics of Financial Markets" Princeton University Press, Princeton, New Jersey, 611 pages.

Campbell J. and Viceira L. (2001), "Who should buy long-term bonds?", American Economic Review, 91, 99-127. 
Chacko G. and Viceira L. (2005) "Dynamic Consumption and Portfolio Choice with Stochastic Volatility in Incomplete Markets”, Review of Financial Studies, 18, 1369-1402

Chun A.L. (2005), "Expectations, bond yields and monetary policy", Working Paper SSRN $\mathrm{n}^{\circ} 685801$.

Del Castillo C. and Fillion J.F. (2002), "Term premium determinants of three-month forward interest rates", Working Paper n ${ }^{\circ} 2002-08$, Department of Finance, HEC Montreal.

Engle R.F. and Ng V. (1993) "Time Varying Volatility and the Dynamic Behavior of the Term Structure", Journal of Money, Credit and Banking, 25, 336-349.

Estrella A. and Hardouvelis G. (1991), "The term structure as a predictor of real economic activity", Journal of Finance, 46, 555-576.

Fama, E. (1984), "The information in the term structure", Journal of Financial Economics, 13, 509-528.

Fama E. (2006), “The behavior of interest rates”, Review of Financial Studies, 19, 359-379.

Ferson W. and Foerster S. (1994), "Finite sample properties of the generalized method of moments in test of conditional asset pricing models", Journal of Financial Economics, 36, 2955 .

Grammig J. and Schrimpf A. (2006), "Consumption-Based Asset Pricing with a Reference Level: New Evidence from the Cross-section of Stock Returns", ZEW discussion paper 06-032. Hansen L. and Singleton K. (1983), "Stochastic consumption, risk aversion and the temporal behaviour of asset returns", Journal of Political Economy, 91, 249-268.

Harvey C. (1988), "The real term structure and consumption growth", Journal of Financial Economics, 22, 305-334.

Hejazi W., Lai H. and Yang X. (2000), “The expectations hypothesis, term premiums and the Canadian term structure of interest rates", Canadian Journal of Economics, 33, 133-148.

Keim D. and Stambaugh R. (1986), "Predicting returns in stock and bond markets", Journal of Financial Economics, 17, 357-390.

Laibson D. (1996), "Hyperbolic discount functions, undersaving and savings policy”, NBER working paper $\mathrm{n}^{\circ} 5635$.

Laibson D. (1998), "Life-cycle Consumption and Hyperbolic Discount Functions”, European Economic Review Papers and Proceedings, 42, 861-871.

Laibson D., Repetto A. and Tobacman J. (2004), "Estimating Discount Functions from Lifecycle Consumption Choices", January working paper, Harvard University.

Lee S. (1995), "Macroeconomic sources of time-varying risk premiums in the term structure of interest rates", Journal of Money, Credit and Banking, 27, 549-569.

Lengwiler Y. (2005), "Heterogeneous patience and the term structure of real interest rates", American Economic Review, 95, 890-896.

Lucas R. (1978), “Asset prices in an exchange economy”, Econometrica 46, 1429-1446.

Ludvingston S. and Ng S. (2009) "A Factor Analysis of Bond Risk Premia”, NBER paper

Malloy C., Moskowitz T. and Vissing-Jorgensen A. (2009), "Long-run stockholder consumption risk and asset returns", Journal of Finance, 64, n 6, 2427-2479.

Mankiw N. and Zeldes S. (1991) "The consumption of stockholders and nonstockholders", Journal of Financial Economics, 29, 97-112

Mehra R. and Prescott E. (1985), "The equity premium: A puzzle", Journal of Monetary Economics, 15, 145-161. 
Paiella M. (2004), "Heterogeneity in financial market participation: Appraising its implications for C-CAPM", Review of Finance, 8, 445-480.

Shiller R. (1990), "The term structure of interest rates" In B. Friedman and F. Hahn (Eds), Handbook of Monetary Economics, 625-722, North Holland.

Strotz R.H. (1956), "Myopia and inconsistency in dynamic utility maximization", Review of Economic Studies, 23, 165-180.

Sundaresan S (1989) "Intertemporally dependent preferences and the volatility of consumption and wealth", Review of Financial Studies, 2, 73-88.

Wachter J. (2006), “A consumption-based model of the term structure of interest rates", Journal of Financial Economics, 79, 365-399.

Weil, P. (1989), "The Equity Premium Puzzle and the Risk-Free Rate Puzzle", Journal of Monetary Economics, 24, 401-421.

\footnotetext{
${ }^{1}$ See art. cit. Table VII.

${ }^{2}$ We obtain $\log \left(R_{\mathrm{j}}\right)=$ j.r.

${ }^{3}$ So we obtain $\operatorname{var}(\mathrm{R})=\operatorname{var}(\Delta \mathrm{i})$ because $\mathrm{R}=\mathrm{R}^{\text {nom }}-\Delta \mathrm{i} . \mathrm{R}^{\text {nom }}$ is the nominal certain rate at time $\mathrm{t}$.

${ }^{4}$ Data are annualized; yields for 1-year and longer maturities are quoted on an annual investment basis. The 6month T. Bill rates on the secondary markets are quoted on a discount basis based on 360 days. They have been converted to annual equivalent yields.

${ }^{5}$ We used a linear interpolation. Nonlinear fittings, for instance a logarithmic one, were considered because of the small number of observations (six points).

${ }^{6}$ Restricted correlation models of GARCH is also tested. Either a diagonal model (no correlation) or a constant correlation model gives lower results. The significant $c^{c, i}$ coefficient in table 3 supports the standard unrestricted version or the AR-ARCH model.

${ }^{7}$ See Campbell, Lo and McKinlay (1997) p.484.

${ }^{8}$ In GMM estimation, the instruments need to be stationary. We used detrained data and considered one-month variation of industrial production, of money supply, and of the S\&P 500 index as instruments.

${ }^{9}$ This test is asymptotic. For finite sample properties, see Ferson and Foerster (1994).

${ }^{10}$ One-stage GMM uses an identity matrix as the weighting matrix. It produces robust estimates, but these weights are not efficient. In a two-stage GMM, the estimators are found by minimizing the function J of the parameter estimates using the first step estimated matrix as weights. The two-stage GMM uses the efficient matrix to weight the moments that produce minimum variance estimates. The Hansen's J-test cannot be used to compare different models because the weighting matrix changes from model to model. Hence, the model with the lowest J-test value is not necessarily the model with the smallest pricing errors. First-stage GMM, though less efficient, is preferable for model comparisons because the average pricing errors for the tested assets are weighted identically across all compared models (Grammig et al., 2006). However, in our tests, we also used two-stage GMM and found similar results with regard to the $\mathrm{J}$-test significance and the individual variable significance.

${ }^{11}$ In that sense, our nonlinear multivariate estimate is partially exposed to an "in-sample" bias.

${ }^{12}$ An unreported preliminary analysis of the term premiums shows a significant cross-correlation between them.

${ }^{13}$ A specification test between unrestricted and restricted forms is done to compare multivariate nonlinear GMM estimates. The conclusions are the same as those drawn from the multivariate linear SUR model.
} 